\title{
An Assessment of the Effects of Shell Crosslinked Nanoparticle Size, Core Composition, and Surface PEGylation on In Vivo Biodistribution
}

\author{
Xiankai Sun $\ddagger, \S$, Raffaella Rossin $\ddagger$, Jeffrey L. Turner ${ }^{\dagger}$, Matthew L. Becker ${ }^{\dagger}$, Maisie J. \\ Joralemon ${ }^{\dagger}$, Michael J. Welch ${ }^{\dagger} \ddagger^{*}$, and Karen L. Wooley ${ }^{*}$ \\ $\$$ Division of Radiological Sciences, Washington University School of Medicine, St. Louis, MO 63110 \\ $\dagger$ Department of Chemistry, Washington University, One Brookings Drive, St. Louis, MO 63130
}

\section{Abstract}

Amphiphilic core-shell nanoparticles have drawn considerable interest in biomedical applications. The precise control over their physico-chemical parameters and the ability to attach various ligands within specific domains suggest shell crosslinked (SCK) nanoparticles may be used as multi-/ polyvalent scaffolds for drug delivery. In this study, the biodistribution of four SCKs, differing in size, core composition, and surface PEGylation was evaluated. To facilitate in vivo tracking of the SCKs, the positron-emitting radionuclide copper-64 was used. By using biodistribution and microPET imaging approaches, we found that small diameter $(18 \mathrm{~nm}) \mathrm{SCKs}$ possessing a polystyrene core showed the most favorable biological behavior in terms of prolonged blood retention and low liver accumulation. The data demonstrated that both core composition, which influenced the SCK flexibility and shape adaptability, and hydrodynamic diameter of the nanoparticle play important roles in the respective biodistributions. Surface modification with poly(ethylene glycol) (PEG) had no noticeable effects on SCK behavior.

\section{Introduction}

Nano-architectures (e.g., nanospheres, nanocapsules, liposomes, micelles, etc.) have long been explored as carriers for delivery of therapeutic and diagnostic agents. ${ }^{1-8}$ However, numerous challenges remain before the full potential of nano-constructs with properties suitable for biomedical applications is realized. ${ }^{9}$ The relatively fast removal of the carriers from the bloodstream by the reticulo-endothelial system (RES) has thus far limited their use as therapeutic and diagnostic agents. Several approaches, including PEGylation strategies, have been taken to reduce the rapid blood clearance of nanoparticulates and maintain a sufficient blood lifetime, which allows the carriers sufficient time to reach their targets. ${ }^{1-3,10-28}$

Among the current nano-carriers, self-assembled constructs, such as micelles, have shown many advantages as potential drug delivery systems. ${ }^{2,13,17,29,30}$ These spherical carriers are formed from the self-assembly of amphiphilic molecules in water. The encapsulation of poorly water soluble pharmaceuticals into the hydrophobic cores of these carriers has been shown to improve the bioavailability and pharmacokinetics of the drugs, as well as provide protection from destructive factors present in vivo. ${ }^{19,31-37}$ However, the in vivo stability of micellar systems is of moderate concern. In vivo, their systemic concentrations can fall below the critical

\footnotetext{
*To whom correspondence should be addressed. Phone: (314) 362-8436, Fax: (314) 362-8399, E-mail: welchm @ mir.wustl.edu, or Phone: (314) 935-7136, Fax: (314) 935-9844, E-mail: klwooley@artsci.wustl.edu.

SCurrent address: Department of Radiology, the University of Texas Southwestern Medical Center, Dallas, TX 75390
} 
micelle concentration (CMC), the point at which thermodynamic stability of the assembled construct may be compromised. However, the CMC depends upon a number of factors including the chemical nature, the respective lengths, and the ratio of hydrophilic and hydrophobic components, allowing for fine tuning of the CMC value for each individual system. 38

Shell crosslinked nanoparticles (SCKs) are amphiphilic core-shell nanoparticles, in which crosslinks are introduced throughout the shell layer of the micellar precursor, providing stability to the nanostructure and thus negating all issues produced by the CMC. ${ }^{39,40}$ The remaining functional groups in the resultant unimolecular structures allow for further derivatization of the nanoparticle, while maintaining diversity in the hydrophobic and hydrophilic components which are utilized to form the structure. The determinants of the SCK size and size distribution are a result of the nature of the amphiphilic copolymer and the conditions for the formation of the micelle, both of which can be controlled precisely leading to narrow size distributions that can vary between 10 and $100 \mathrm{~nm} .{ }^{41}$ Other SCK properties, such as the surface functionality and the hydrophilicity, density, and porosity of the core and shell, can also be easily controlled. ${ }^{42}$ Recently, it has been found that these core-shell nanoparticles are capable of hydrophobic guest sequestration and transport, ${ }^{43}$ packaging DNA while the SCK surface bears positively-charged functional groups, ${ }^{44}$ cell membrane transduction when derivatized with a HIV protein transduction domain peptide sequence, ${ }^{45}$, 46 and tissue-specific targeting via receptor-ligand interactions, e.g. with folic acid ${ }^{47}$ and saccharide ${ }^{48}$ ligands. The ease of control over the structural and chemical features, which play a critical synergistic role in their biomedical properties, suggests that SCKs may be suitable nanoscale scaffolds for the transport and delivery of biologically active agents. ${ }^{46-50}$

Positron emission tomography (PET) is a nuclear imaging modality that provides non-invasive functional images with high sensitivity and specificity, and enables quantitative imaging analysis for the detection of in vivo abnormalities. In recent years, copper radiotracers have emerged as promising PET imaging $51-57$ and radiotherapeutic agents. ${ }^{58-62}$ Among the four copper radionuclides used in PET tracers $\left({ }^{64} \mathrm{Cu},{ }^{62} \mathrm{Cu},{ }^{61} \mathrm{Cu}\right.$, and $\left.{ }^{60} \mathrm{Cu}\right),{ }^{64} \mathrm{Cu}$ has shown great potential in PET imaging and radiotherapy applications because of its desirable decay characteristics $\left(\mathrm{t}_{1 / 2}=12.7 \mathrm{~h} ; \beta^{+}: 0.653 \mathrm{MeV}, 17.4 \% ; \beta^{-}: 0.578 \mathrm{MeV} ; 39 \%\right)$ and the ability to produce it in high yield and specific activity on small biomedical cyclotrons. 63,64

While our eventual goal is to develop the core-shell nanospheres as biocompatible scaffolds that will provide multi-/polyvalent presentation of functionalities for detection, diagnosis, and intervention of disease states by coupling various functional molecules to SCKs, the first challenge is to optimize the pharmacokinetics of SCKs in order to avoid the rapid clearance from the bloodstream by the RES upon intravenous administration. In this report, we present an approach to radiolabel SCKs with ${ }^{64} \mathrm{Cu}$ via conjugation of a TETA $(1,4,8,11$ tetraazacyclotetradecane-1,4,8,11-tetraacetic acid) derivative, and investigate the effects of core composition, hydrodynamic size, and surface modification with PEG on the behavior of ${ }^{64} \mathrm{Cu}$-labeled SCKs in vivo by conventional biodistribution and microPET imaging studies.

\section{Experimental Procedures}

\section{Materials}

All chemicals were purchased from Sigma-Aldrich (St. Louis, MO) and used without further purification unless otherwise noted. Copper-64 was prepared on the Washington University Medical School CS-15 Cyclotron by the ${ }^{64} \mathrm{Ni}(\mathrm{p}, \mathrm{n}){ }^{64} \mathrm{Cu}$ nuclear reaction at a specific activity of $50-200 \mathrm{mCi} / \mu \mathrm{g}$ at the end of bombardment, as previously described ${ }^{64}$ Water was distilled and then deionized (18 M $\Omega-\mathrm{cm}$ ) by means of a Milli-Q water filtration system (Millipore Corp., Bedford, MA). TETA was purchased from Macrocyclics (Dallas, TX). Sodium hydroxide was 
purchased from LabChem (Pittsburgh, PA). Saline ( $0.9 \% \mathrm{NaCl}$ solution) was purchased from American Pharmaceutical Partners (Schaumburg, IL). Centricons (YM-30: MWCO 30 kDa; YM-100: MWCO $100 \mathrm{kDa}$ ) were purchased from Millipore. Dialysis tubing was purchased from Spectrum Laboratories (Rancho Dominguez, CA) and hydrated for at least one hour prior to use. Normal phase silica gel thin layer chromatography (TLC) plates (60 F254) were purchased from EMD Chemical Inc (Gibbstown, $\mathrm{NJ}$ ) and reverse phase Waters $\mathrm{C} 18$ silica gel TLC plates (KC18F, 60§, $200 \mu \mathrm{m})$ were purchased from Fisher Scientific (Pittsburgh, PA). Radio-TLC was performed using a Bioscan 200 imaging scanner (Bioscan, Washington, DC). Fast protein liquid chromatography (FPLC) and radio-FPLC were performed using an Amersham Pharmacia Biotech ÄKTA FPLC (Amersham Biosciences, Piscataway, NJ) equipped with a Beckman 170 Radioisotope Detector (Beckman Instruments, Fullerton, CA).

\section{General Procedure for Diblock Copolymer Formation}

Poly ( $t$-butyl acrylate) homopolymers were prepared by atom transfer radical polymerization of $t$-butyl acrylate using ethyl-2-bromopropionate as the initiator and copper(I) bromide and $N, N, N^{\prime}, N$ ', $N$ ' '-pentamethyldiethylenetriamine as the catalyst and ligand, respectively. The resulting $t$-butyl acrylate homopolymer was subsequently utilized as an initiator for growth of methyl acrylate, styrene, or deuterated styrene, to form a diblock copolymer. All polymerizations were carried out in an inert atmosphere at elevated temperatures $\left(50-75^{\circ} \mathrm{C}\right)$. Conversion to the amphiphilic diblock copolymers was accomplished through acidolysis of the $t$-butyl ester segments with trifluoroacetic acid (TFA) for $\sim 24 \mathrm{~h}$, as monitored by ${ }^{1} \mathrm{H}$ NMR spectroscopy.

General Procedure for Micelle Formation (see Supplemental Information for details). To a stirred solution of the amphiphilic diblock copolymer $(\sim 2 \mathrm{mg} / \mathrm{mL})$ in tetrahydrofuran, an equal volume of water or phosphate buffered saline (PBS) was added slowly at a constant rate ( 10 $\mathrm{mL} / \mathrm{h})$. The resultant solution was allowed to dialyze against water or buffer for several days to afford the micellar structure in aqueous solution.

\section{General Procedure for SCK Nanoparticle Formation}

$2,2^{\prime}$-(Ethylenedioxy)-bis(ethylamine) ( 0.25 molar equivalents to acid functionalities) was added to the micellar solution $(\sim 0.5 \mathrm{mg} / \mathrm{mL})$ as a dilute aqueous solution. Following a brief equilibration period ( $30 \mathrm{~min})$, an aqueous solution $(100 \mathrm{mg} / \mathrm{mL})$ of $1-\left(3^{\prime}-\right.$

dimethylaminopropyl)-3-ethylcarbodiimide (EDC) hydrochloride or EDC methiodide was added slowly to induce cross-linking. The reaction mixture was allowed to stir for $24 \mathrm{~h}$, and the SCK nanoparticle solution was purified through dialysis or continuous passage through a concentration cell membrane.

\section{General Procedure for Poly(ethylene glycol) Conjugation onto the SCK}

PEGylation of the SCKs was conducted by slight modification of a previously reported procedure. ${ }^{47}$ Monoamine polyethylene oxide of molecular weight $5240 \mathrm{Da}$ was added to the aqueous solution and allowed to stir for $24 \mathrm{~h}$. A dilute aqueous solution of EDC hydrochloride or EDC methiodide was added to the reaction vessel and allowed to stir for $24 \mathrm{~h}$. The resultant SCK solution was dialyzed extensively in dialysis tubing (MWCO $12-14 \mathrm{kDa}$ ) against nanopure water to remove non-reacted monoamino polyethylene oxide, excess carbodiimide coupling agent and the urea reaction byproduct.

\section{Synthesis of $\mathbf{N}$-Butoxycarbonyl-[2,2'-(ethylenedioxy)bis(ethylamine)]}

A modified version of a previously reported synthetic procedure was followed. ${ }^{65}$ To an excess of 2,2'-(ethylenedioxy)bis(ethylamine) $(4.063 \mathrm{~g}, 27.4 \mathrm{mmol})$ in 1,4 dioxane $(40 \mathrm{~mL})$, di-t-butyl dicarbonate $(1.213 \mathrm{~g}, 5.56 \mathrm{mmol})$ in 1,4 dioxane $(20 \mathrm{~mL})$ was added dropwise over a 30 minute 
period at room temperature (RT) under nitrogen. The reaction was allowed to stir for 3.5 additional hours at RT. The solvent was removed in vacuum and the residue was taken up into water, filtered, and extracted with dichloromethane $(3 \times 20 \mathrm{~mL})$. The organic layer was collected, dried over sodium sulfate, and dried in vacuum, to yield a slightly yellow oil in $46 \%$ yield $(0.635 \mathrm{~g}, 2.56 \mathrm{mmol}) .{ }^{1} \mathrm{H}$ NMR $\left(300 \mathrm{MHz}, \mathrm{CDCl}_{3}, \delta, \mathrm{ppm}\right): 5.6(1 \mathrm{H}, \mathrm{b}), 3.60(4 \mathrm{H}, \mathrm{s})$, $3.45(4 \mathrm{H}, \mathrm{m}), 3.25(2 \mathrm{H}, \mathrm{m}), 2.80(2 \mathrm{H}, \mathrm{t}), 1.40(9 \mathrm{H}, \mathrm{s}) ;{ }^{13} \mathrm{C} \mathrm{NMR}\left(75 \mathrm{MHz}, \mathrm{CDCl}_{3}, \delta, \mathrm{ppm}\right)$ : $156.2,78.7,73.3,69.8,66.7,41.5,39.9,28.4$.

\section{Synthesis of Amino Functionalized TETA Chelator (TETA-NH ${ }_{2}$ )}

TETA $(0.404 \mathrm{~g}, 0.699 \mathrm{mmol})$ was dissolved in water $(60 \mathrm{~mL})$ and the $\mathrm{pH}$ of the solution was adjusted to 5 through dropwise addition of sodium hydroxide. To this solution, $N$ butoxycarbonyl-[2,2'-(ethylenedioxy)bis(ethylamine)] (0.0856 mg, $0.344 \mathrm{mmol})$ in water (20 $\mathrm{mL}$ ) was added dropwise over a $20 \mathrm{~min}$ period. The reaction mixture was allowed to stir for $15 \mathrm{~min}$ prior to the dropwise addition of EDC methiodide $(0.249 \mathrm{~g}, .839 \mathrm{mmol})$ in water $(20$ $\mathrm{mL}$ ) over a 15 min period. The reaction mixture was allowed to stir for $16 \mathrm{~h}$ at RT, and was subsequently dried in vacuum. The residual solid was triturated with methanol and filtered. The resulting methanol solution was concentrated in vacuum and precipitation was induced through the addition of acetone. The resulting white solid was pelleted via centrifugation, dried under vacuum, and redissolved into methanol. The precipitation procedure was repeated an additional seven times to yield a white solid, which was dissolved into a 1:2 mixture of water and tetrahydrofuran $(45 \mathrm{~mL})$, and $7 \mathrm{~mL}(90 \mathrm{mmol})$ of TFA was added. The resulting mixture was allowed to stir over a 2-h period at RT. The solution was again dried in vacuum and precipitated to yield a mixture of amino functionalized and unfunctionalized TETA in a 53:47 ratio, as determined by ${ }^{1} \mathrm{H}$ NMR spectroscopy (ratio of methylene protons adjacent to ether units, at $3.85 \mathrm{ppm}$, and methylene protons from macrocycle, at $2.00 \mathrm{ppm}$ ), in a $25 \%$ yield.

${ }^{1} \mathrm{H}$ NMR (300 MHz, $\mathrm{D}_{2} \mathrm{O}, \delta$, ppm): 3.85, 3.50, 3.40-2.60, 2.20, 2.00; ${ }^{13} \mathrm{C}$ NMR $(75 \mathrm{MHz}$, $\left.\mathrm{D}_{2} \mathrm{O} / \mathrm{CD}_{3} \mathrm{CN}, \delta, \mathrm{ppm}\right): 181.5,179.5,73.5,72.3,71.6,56.8,56.6,56.3,53.7,53.3,53.1,47.1$, 46.9, 27.1, 26.3; IR (Diffuse Reflectance, $\mathrm{cm}^{-1}$ ) 3632, 3571, 2996, 2945, 2867, 2372, 2342, 1847, 1774, 1737, 1720, 1638, 1544, 1477, 1461, 1439, 938, 889, 863.

\section{Conjugation of SCKs with TETA- $\mathrm{NH}_{2}$}

The conjugation was done by a modified procedure for DOTA-antibody conjugation via the $N$-hydroxysuccinimide route. ${ }^{66,67}$ Briefly, it consists of two steps: (1) preparation and separation of sulfo-NHS-SCK ester; and (2) coupling the activated ester with TETA-NH ${ }_{2}$. The sulfo-NHS-SCK ester was formed by the reaction of SCK with $N$-hydroxysulfosuccinimide (sulfo-NHS) under the activation by EDC hydrochloride in $10 \mathrm{mM}$ PBS (pH was adjusted to 5.5 ) at $4{ }^{\circ} \mathrm{C}$ for $2 \mathrm{~h}$. The molar ratio of sulfo-NHS : SCK (surface carboxylate groups) : EDC was approximately 10:5:1. The reaction mixture was centrifuged at least five times through a Centricon YM-30 with $10 \mathrm{mM}$ PBS (pH 5.5) to ensure the complete separation of the activated ester from EDC and sulfo-NHS. The purified sulfo-NHS-SCK ester was then reacted with TETA- $\mathrm{NH}_{2}$ in $10 \mathrm{mM}$ PBS (pH was adjusted to 7.5 ) at $4{ }^{\circ} \mathrm{C}$ for $12-16 \mathrm{~h}$. The mole ratio of sulfo-NHS-SCK ester (surface sulfo-NHS ester groups) : TETA-NH ${ }_{2}$ was $~ 1: 2$. After conjugation, the reaction mixture was again centrifuged at least five times through a Centricon YM-30 with $10 \mathrm{mM}$ PBS (pH 7.4) to remove unreacted TETA- $\mathrm{NH}_{2}$. The final product, the TETA-SCK conjugate, was reconstituted in $10 \mathrm{mM}$ PBS (pH 7.4) to a concentration of $0.2-$ $0.5 \mathrm{mg} / \mathrm{mL}$ and stored at $4{ }^{\circ} \mathrm{C}$ for further use. The concentrations of SCK before and after conjugation were monitored by the UV spectrophotometer of FPLC.

\section{Radiolabeling of TETA-SCK Conjugates with ${ }^{64} \mathrm{Cu}$}

Copper-64 chloride (typically in $0.1 \mathrm{M} \mathrm{HCl}$ ) was converted to ${ }^{64} \mathrm{Cu}$-acetate by adding an appropriate volume of $0.1 \mathrm{M}$ ammonium acetate buffer (pH 7.0) to the ${ }^{64} \mathrm{CuCl}_{2}$ solution. To 
$400 \mu \mathrm{L}$ of a TETA-SCK solution, $20 \mu \mathrm{L}$ of ${ }^{64} \mathrm{Cu}$-acetate was added $(2-5 \mathrm{mCi})$. The resulting solution was incubated at $43{ }^{\circ} \mathrm{C}$ for $2-4 \mathrm{~h}$ in a thermomixer (1,000 rpm). After incubation, 5 $-10 \mu \mathrm{L}$ of $10 \mathrm{mM}$ diethylenetriaminepentaacetic acid (DTPA) solution was added to the ${ }^{64} \mathrm{Cu} / \mathrm{TETA}-\mathrm{SCK}$ solution. The solution was vortexed for a few seconds and left at RT for $10 \mathrm{~min}$. It was then centrifuged at least two times through a Centricon YM-100 with $10 \mathrm{mM}$ PBS (pH 7.4) to remove the ${ }^{64} \mathrm{Cu}$-DTPA complex and/or the free ${ }^{64} \mathrm{Cu}$-activity. The radiochemical purity (RCP) of the ${ }^{64} \mathrm{Cu}$-labeled TETA-SCK nanoconjugate was monitored by FPLC. The product was then diluted with $10 \mathrm{mM}$ PBS (pH 7.4) to prepare appropriate doses for biodistribution and imaging studies.

\section{FPLC Analysis}

A $100 \mu \mathrm{L}$ of analyte was injected into a Superose 12 gel filtration column (Amersham Biosciences, Piscataway, NJ), which was then eluted with $20 \mathrm{mM}$ Hepes and $150 \mathrm{mM} \mathrm{NaCl}$ (pH 7.3) buffer at an isocratic flow rate of $0.5 \mathrm{~mL} / \mathrm{min}$. The UV wavelength was preset to 280 $\mathrm{nm}$ and the radioactivity was monitored by an in-line Beckman radio-detector. Under these conditions, the retention times of the SCK and TETA-SCK nanoconjugates were $\sim 15 \mathrm{~min}$. Samples having over $90 \%$ RCP were used for animal studies.

\section{Titration of TETA-SCK Nanoconjugates}

To estimate the number of TETA groups attached to the SCKs, a TETA titration was carried out by a modified isotopic dilution method. ${ }^{51}$ Briefly, ${ }^{64} \mathrm{Cu}$-acetate $(50-100 \mu \mathrm{Ci})$ was added to $5-7$ solutions containing amounts ranging from $0.1 \times 10^{-3}$ to $5.0 \times 10^{-3} \mu \mathrm{mol}$ of nonradioactive $\mathrm{CuCl}_{2}$ in $0.1 \mathrm{M}$ acetate buffer ( $\mathrm{pH}$ 6.5). The "hot plus cold" $\mathrm{Cu}$-acetate solutions with different specific activities were then added to aliquots of the SCK solutions $(50 \mu \mathrm{g} /$ sample) and the labeling mixtures were allowed to incubate for $6 \mathrm{~h}$ at $43^{\circ} \mathrm{C}$. After incubation, $0.1 \mu$ mol ethylenediaminetetraacetic acid (EDTA) was added to the solutions, which were then incubated for $10 \mathrm{~min}$ at RT. The solutions were spotted on silica gel TLC plates, which were developed in methanol/10\% acetate (v/v: 1/1) and analyzed by a Bioscan 200 TLC scanner. The Cu-labeled nanoparticles remained at the origin, while the Cu-EDTA complex migrated with an $R_{f}$ of 0.8. The number of chelates attached to the nanoparticles was determined from the percent labeling efficiency (obtained from the radio-TLC) and the total amount of copper added:

$$
n(\text { chelates })=\frac{n(\text { copper }) \times \text { LabelingEfficiency }(\%)}{100}
$$

\section{Biodistribution Studies}

All animal studies were performed in compliance with guidelines set by the Washington University Animal Studies Committee. Copper-64 labeled SCK solutions were diluted with saline. Normal mature female Sprague-Dawley rats weighing 180-200 g ( $\mathrm{n}=4$ per time point) were anesthetized with $1-2 \%$ vaporized isoflurane and injected with $\sim 10 \mu \mathrm{Ci}$ of activity via the tail vein. The injected volume of activity per rat was $150 \mu \mathrm{L}$. The rats were anesthetized prior to sacrifice at each time point. Organs and tissues of interest were removed, wet-weighed, and counted. For blood, bone, and muscle, total activity was calculated assuming that these tissues constitute 6,11 , and $41 \%$ of the total weight, respectively. Diluted standard doses $(1: 100)$ were prepared and counted along with the samples. All the data were corrected for radioactive decay of copper-64.

The percent injected dose per gram tissue $(\% \mathrm{ID} / \mathrm{g})$ and the percent injected dose per organ $(\%$ ID/organ) values were calculated using the following equations:

$\% I D / g=\frac{(\text { cpm in sample }- \text { background }) \times 10^{2}}{(\text { decay correction factor }) \times(\text { sample weight }) \times(\text { cpm in standard })}$ 


$$
\% I D / \text { organ }=\frac{(\mathrm{cpm} \text { in sample }- \text { background }) \times 10^{2}}{(\text { decay correction factor }) \times(\text { cpm in standard })}
$$

\section{Small Animal PET Imaging Studies}

The imaging studies were carried out using the MicroPET ${ }^{\circledR}$ R4 (rodent) scanner (Concorde Microsystems, Knoxville, TN). ${ }^{68}$ Normal Balb/c mice weighing $20-30 \mathrm{~g}(\mathrm{n}=2)$ were anesthetized with $1-2 \%$ vaporized isoflurane and injected with $\sim 100-500 \mu \mathrm{Ci}$ of labeled SCKs $(4-5 \mathrm{mg} / \mathrm{kg}$ mouse weight) in $150 \mu \mathrm{L}$ saline via the tail vein. At specific time points, the mice were re-anesthetized and then immobilized in a supine position on custom-built support beds, with attached anesthetic gas nose cones, for data collection. Within $4 \mathrm{~h}$ post injection (p.i.), the imaging collection time was $10 \mathrm{~min}$; at $24 \mathrm{~h}$ p.i., the imaging collection time was 20 min. The radioactive tracer accumulation $\left({ }^{64} \mathrm{Cu}\right.$-labeled SCK) in a targeted organ was measured using the standardized uptake value (SUV). The SUVs were obtained by the quantification of the regions of interest (ROIs) by viewing these areas in the selected tissues and averaging the activity concentration corrected for decay over the contained voxels (three image slices/organ in selected organs and tumors from two animals) at the time points p.i. 69

$$
\mathrm{SUV}=\frac{\text { Radioactivity Concentration in } \mathrm{ROI}[\mu \mathrm{Ci} / \mathrm{cc}]}{\text { Injection Dose }[\mu \mathrm{Ci}] / / \text { Animal Weight }[\mathrm{g}]}
$$

One-way analysis of variance (ANOVA) and post-hoc multiple comparison (Bonferroni's ttest) on the biodistribution (\%ID/g) and SUV data were performed using Prism v. 4.00 (Graphpad, San Diego, CA).

\section{Results and Discussion}

The synthesis of the SCK is conceptually straightforward (Scheme 1): beginning from an amphiphilic diblock copolymer, self-assembly is induced by the slow addition of water to the solvated polymer solution. The resultant micellar structure is subsequently crosslinked to afford a robust and discreet nanoparticle, with a number of potential applications in biological systems. ${ }^{43,44,46-48,50}$ Thus far, limited studies have demonstrated that the SCKs do not affect cell viability in vitro at physiologically relevant concentrations and that any immunogenic response typically exhibits dose and concentration dependence on the functional species that are attached. ${ }^{45,70}$ A small animal study consisting of a series of intraperitoneal injections of SCKs derivatized with increasing numbers of peptides resulted in insignificant increases in serum IgG at all but the highest numbers of peptides and no gross abnormalities were revealed in post mortem organ histology. ${ }^{45}$ The next step in our efforts to apply these materials to increasingly sophisticated multi- and polyvalent detection, diagnosis, and intervention applications requires a detailed evaluation of how the underlying SCK physicochemical parameters contribute to the systemic clearance and biodistribution in live animals.

Given that biological processes are dominated by molecular-level interfacial interactions, it was expected that the flexibility and shape adaptability of the SCKs would play a role in their behaviors in vivo, in addition to the obvious influences of hydrodynamic diameter and surface chemistry. Shell cross-linked nanoparticles have been shown to display varying degrees of compositional dependent flexibilities when in contact with substrates. Specifically, SCKs containing partially hydrochlorinated poly(isoprene) cores were shown to undergo deformation at temperatures above their glass transition temperature $\left(\mathrm{T}_{\mathrm{g}}\right) .{ }^{72}$ The impact of particle rigidity on surface contact area is significant. Previous research from the laboratory of Tsuchida has demonstrated that for phospholipid vesicles $(\sim 1 \mu \mathrm{m})$, membrane flexibility plays an important role in surface interactions of platelet membrane glycoprotein (rGPIb $\alpha$ ) labeled vesicles with a von Willebrand factor labeled surface. ${ }^{73}$ Particles containing greater degrees of flexibility were shown to undergo reduced lateral speed across the surface, which was hypothesized to 
result from an increased binding ability of the particle with the surface. Biological processes are dominated by surface mediated interactions and so considerations on how a mobile surface contact area affects nanoparticle biodistribution in vivo led us to synthesize SCKs of two distinct diameters possessing a low $\mathrm{T}_{\mathrm{g}}$ fluid-like poly(methyl acrylate) (PMA) core and a high $\mathrm{T}_{\mathrm{g}}$ glassy poly(styrene) (PS) core to systematically examine these effects.

As is presented in Table 1, four SCKs were synthesized, characterized, and then utilized for these in vivo studies. Two of the SCKs, one small and one big, contained poly(methyl acrylate) within their core domains, and are designated as SCKsac and SCKbac, respectively, where "s" vs. "b" indicates a small vs. big particle size, and "ac" indicates an acrylate core material. The other two SCKs, one small and one big, contained polystyrene within their cores, and are designated according to the same nomenclature as SCKssc and SCKbsc, respectively. The nanoparticles were designated as small vs. big based on the number average hydrodynamic diameters $\left(D_{h}\right)$ determined from dynamic light scattering (DLS), where the SCKsac and SCKssc exhibited similar diameters of $24 \pm 3 \mathrm{~nm}$ and $18 \pm 4 \mathrm{~nm}$, respectively, and the SCKbac and SCKbsc were of similar diameters of $37 \pm 4 \mathrm{~nm}$ and $37 \pm 2 \mathrm{~nm}$, respectively. These relative differences in size were also observed in the weight-average molecular weights $\left(M_{p}\right)$ that were determined from a combination of analytical ultracentrifugation (AU) and density measurements, and in the aggregation numbers $\left(\mathrm{N}_{\mathrm{agg}}\right.$, number of polymer chains/SCK). The small SCKs had lower $\mathrm{M}_{\mathrm{p}}$ 's and thus smaller $\mathrm{N}_{\mathrm{agg}}$ 's than the larger nanoparticles. Again the small SCKs were similar relative to each other, as were the large SCKs. Each of the four particles presented similar surface chemistry, having undergone the same crosslinking reactions to the same extent, and exhibited similar zeta potential values $(\zeta)$.

To enable the in vivo evaluation by small animal PET imaging and biodistribution studies, ${ }^{64} \mathrm{Cu}$ was used, as it has been proven to be a versatile isotope in diverse applications in PET imaging and cancer radiotherapy. ${ }^{71}$ TETA $(1,4,8,11$ -

tetraazacyclotetradecane-1,4,8,11-tetraacetic acid) has been used traditionally as a chelator for copper in radiopharmaceuticals. ${ }^{71}$ To attach ${ }^{64} \mathrm{Cu}$ to the respective SCK populations, a bifunctional chelator (BFC), formed from amidation of a single carboxylic acid of TETA with a monoprotected diamine was designed and synthesized. Removal of the protecting group, afforded an amino functionalized TETA (TETA- $\mathrm{NH}_{2}$ ), which was conjugated to the acrylic acid residues of the SCK nanoparticle. The nanoparticle-BFC coupling reaction was carried out using a modified procedure for coupling 1,4,7,10-tetraazacyclododecane-1,4,7,10tetraacetic acid (DOTA) with monoclonal antibodies. ${ }^{66,67}$ However, because TETA- $\mathrm{NH}_{2}$ has both carboxylate and amine groups, the BFC molecules were found to undergo selfcondensation reactions in the presence of EDC and sulfo-NHS, and thus resulted in minimal conjugation to the SCK. To avoid this complication, the acid residues within the SCK shell were activated using EDC hydrochloride and sulfo-NHS first, and then the excess EDC was removed via centrifugation using Centricon YM-30 (Scheme 2). Introduction of the amine functionalized TETA compound following centrifugation thereby facilitated the conjugation to the SCK shell.

Radiolabeling of the SCK samples was accomplished through incubation of ${ }^{64} \mathrm{Cu}$-acetate with the TETA-functionalized nanoparticles. Non-specific ${ }^{64} \mathrm{Cu}$ binding within the amide and acid environment that comprises the shell layer of the particle was overcome by adding a second unlabeled and nonconjugated chelating ligand, DTPA, to the labeling mixture. ${ }^{71}$ The DTPA challenge was successful in removal of weakly bound ${ }^{64} \mathrm{Cu}$, thereby ensuring all ${ }^{64} \mathrm{Cu}$ was coordinated specifically within the stable TETA macrocycles conjugated to the SCKs. All of the TETA-conjugated nanoparticles showed greater than $40 \%$ radiolabeling yields and greater than $90 \%$ RCP following the DTPA challenge and separation, as determined by radio-FPLC. This indicated unambiguously that BFC molecules were linked covalently to the SCKs. The number of BFC molecules attached to each of the SCK populations was measured to be at least 
two per nanoparticle by an EDTA back titration of ${ }^{64} \mathrm{Cu}(\mathrm{II}) / \mathrm{Cu}(\mathrm{II})$ and TETA-SCK solutions, a modified isotopic dilution procedure. ${ }^{51}$

In the studies described herein, we have used both biodistribution and microPET imaging to evaluate the fate of ${ }^{64} \mathrm{Cu}$-labeled SCKs in vivo, focusing our attention on blood retention and accumulation in the main excretory organs (liver, spleen, kidney, lungs). Longevity in the bloodstream is a highly demanded feature for a drug delivery system, giving the carriers enough time to reach their targets and/or to release their cargo in a continuous and controlled fashion. ${ }^{9}$ In order to avoid rapid blood clearance, administered particles must retard opsonization and macrophage recognition which results in sequestration by organs of the RES, such as the liver and spleen. Furthermore, injected particles (and their aggregates) should be small and deformable enough to avoid filtration through the lung capillary bed and the splenic interendothelial cell slits. ${ }^{16}$ The introduction of poly(ethylene glycol) (PEG) onto a drug delivery system, has been well-documented in numerous studies and is now the most promising method to avoid the fast removal of the carriers from the bloodstream by the RES, ${ }^{1,11-15}$, $18,20,74,75$ and alter the biodistribution to achieve optimal pharmacokinetics. ${ }^{75}$ Therefore, the incorporation of PEG onto the nanoparticle surface was accomplished as a means to determine its effects on the biodistribution behavior of the SCK nanoconjugates. PEG was attached to the SCKs through carbodiimide-mediated coupling of an amino functionalized poly (ethylene glycol) ( 5000 Da). Following an established procedure that used a chromophorelabeled PEG to quantify the coupling efficiency, ${ }^{47}$ the PEGylation chemistry of this study was conducted to consume nominally $5 \%$ of the acrylic acid residues within the shell of the particle.

\section{Biodistribution Studies}

Blood retention time of the native SCKs and the PEGylated derivatives are presented in Figure 1. Among the native particles studied, the small nanoparticles demonstrated an initial (10 min p.i.) higher blood retention compared to their larger counterparts (SCKsac vs. SCKbac and SCKssc vs. SCKbsc; P < 0.001). For the PS containing SCKs, more than 50\% of the SCKssc injected dose remained in the bloodstream for up to $1 \mathrm{~h}$, while only $~ 5 \%$ of SCKbsc was still circulating at the same time point (Fig.1, bottom panel). Thereafter, SCKssc blood accumulation remained significantly higher than SCKbsc at $4 \mathrm{~h}$ p.i. $(\mathrm{P}<0.001)$ and reached a similar value at $24 \mathrm{~h}$ p.i. For the PMA containing SCKs, SCKsac exhibited slightly but significantly higher blood retention $(\mathrm{P}<0.001)$ compared to SCKbac (Table 2$)$ at each considered time point. Interestingly, despite being of a similar size range (SCKssc: $18 \pm 4 \mathrm{~nm}$; SCKsac: $24 \pm 3 \mathrm{~nm}$ ), SCKssc showed considerably higher accumulation and longer retention in blood compared to SCKsac out to $4 \mathrm{~h}$ p.i. $(\mathrm{P}<0.001)$, supporting the importance of the internal chemical composition, and resulting particle rigidity, in providing a long circulation in blood.

Evaluation of the effects of PEG addition to the SCK surface gave discordant results (Figure 1). Both the parent SCKbsc nanoparticle and its PEGylated derivative exhibited a steady yet low accumulation in blood throughout the experiment and no significant differences were observed before and after PEGylation at all time points. The smaller PS containing SCK (SCKssc) did show significantly higher initial blood uptake at 10 min p.i. $(\mathrm{P}<0.01)$, as compared to its PEGylated counterpart, with a similar clearance profile thereafter. Conversely, the addition of PEG to the SCKbac nanoparticle surface significantly increased the blood accumulation $(\mathrm{P}<0.001)$ at all considered time points whereas SCKsac PEGylation didn't modify blood retention at all considered time points.

Shortly after administration in vivo, massive uptake levels of PEG-SCKbsc in lungs was observed (Figure 2). Reasonably, the filtration through the lung tissue, which is the first capillary bed SCKs encounter upon intravenous injection, is the result of nanoparticle aggregation due to changes in stability of the nanoparticle suspensions. In fact, the PEGylated 
SCKbsc and, to a minor extent, the native SCKbsc demonstrated flocculation when concentrated in solution during the centricon purification steps performed after TETA-NH 2 conjugation and ${ }^{64} \mathrm{Cu}$-radiolabeling. Particle PEGylation had minor effects on lung uptake of other nanoparticles. However, these effects were again discordant among the different nanoparticles. A significant higher lung uptake of native SCKssc compared to PEG-SCKssc was observed up to $1 \mathrm{~h}$ p.i. $(\mathrm{P}<0.001)$. Conversely, shortly after tail vein injection, the SCKbac exhibited a slightly lower lung uptake compared to its PEGylated counterpart $(\mathrm{P}<0.01)$, with a less effective clearance thereafter. Similar lung uptake of SCKsac and PEG-SCKsacwas observed at all time points.

Surprisingly, markedly different lung retention was observed when administering ${ }^{64} \mathrm{Cu}$ radiolabeled SCKbsc and PEG-SCKbsc to different rodent species. In fact, biodistribution data obtained in Sprague/Dawley rats showed an abnormally high lung accumulation of PEGSCKbsc, while microPET images (Figure 9) and data analysis (Figure 6) in Balb/c mice clearly showed high and persistent accumulation of non-PEGylated SCKbsc in lung. Because of such incongruous results in different animal species, we decided not to evaluate the statistical correlation between biodistribution results and microPET data analyses.

Among the considered organs, the liver accumulated the largest portions of the administered SCKs (Figure 3). Within the liver, native and PEGylated SCKbac and SCKsac, and native SCKbsc exhibited similar distribution profiles, with a fast accumulation in the first 10 min p.i. followed by clearance out to $24 \mathrm{~h}$ p.i. Noticeably, the initial uptake of SCKssc and PEG-SCKssc per gram liver was the lowest observed among the nanoparticles studied. These small SCKs with PS core revealed a steady hepatic accumulation up to $4 \mathrm{~h}$ after administration followed by hepatobiliary excretion out to $24 \mathrm{~h}$.

The biodistribution data relative to SCK accumulation in spleen are shown in Figure 4. Contrary to what was observed in the liver, the addition of PEG to the SCK surface did show some beneficial effects in the spleen. Except in the case of SCKsac, all the PEGylated nanoparticles had a more effective splenic clearance out to $24 \mathrm{~h}$ p.i. as compared to their non-PEGylated counterparts. The apparent low PEG-SCKbsc splenic uptake at early time points is a probable consequence of the massive nanoparticle sequestration in the lungs. Overall, the SCK uptake in spleen appears not to depend on size or chemical composition alone. In fact, the small SCK with PS core (SCKssc) and the big SCK with PMA core (SCKbac) exhibit rather low spleen uptake, while the small SCK with PMA core (SCKsac) and the big SCK with PS core (SCKbsc) have a high accumulation, especially at early time points p.i.

In the kidneys, all the particles exhibited an increasing uptake up to $4 \mathrm{~h}$ p.i. followed by a decrease out to $24 \mathrm{~h}$ (Figure 5). After $4 \mathrm{~h}$ p.i., the large nanoparticles demonstrated a moderately higher kidney uptake as compared to the smaller ones. The addition of PEG to the SCKs has no noticeable effect on kidney uptake and clearance.

\section{MicroPET Imaging}

Owing to variability in SCK labeling yield, the microPET imaging was carried out injecting mice different amounts of radioactivity (ca. 100-500 $\mu \mathrm{Ci}$ ) to administer comparable amounts of SCKs (4-5 mg/kg mouse weight). Except for the lung and liver uptake of SCKbsc, the microPET images (Figure 7-Figure 10) show a general concordance with the biodistribution studies. Nanoparticle accumulation within the liver is prominent and persistent out to 24 h p.i. regardless of visible radioactivity hepatobiliary excretion through the intestine. It is noteworthy that, following administration of ${ }^{64} \mathrm{Cu}$-labeled PEG-SCKssc, the mice hearts were clearly imaged out to $24 \mathrm{~h}$ p.i., confirming the presence of the nanoparticles in the blood stream, whereas with the parent SCK the hearts were only visible within $1 \mathrm{~h}$ p.i. (Figure 10). 
The quantitative analyses obtained from microPET images (Figure 6) confirmed that surface PEGylation altered blood retention of SCKssc, as indicated by the significantly higher heart SUV at each considered time point $(\mathrm{P}<0.001)$. In contrast with the biodistribution data, however, PEG-SCKssc exhibits a higher liver uptake compared to SCKssc at $4 \mathrm{~h}$ and $24 \mathrm{~h}$ p.i.

To summarize, when comparing the biodistributions of differently-sized SCKs having PS in their cores (SCKbsc vs. SCKssc), higher uptake of the big SCK in all the considered organs (lung, liver, spleen, and kidney) up to $1 \mathrm{~h}$ p.i. was observed. Thereafter, liver and spleen clearance was slightly more efficient for SCKbsc compared to SCKssc. Such different accumulation in the main excretory organs, especially at early time points, had dramatic effects on the blood circulation (Figure 1). A biunivocal correlation between size and nanoparticle sequestration by liver, spleen, lung, etc., however, was not found by comparison of the biodistributions of flexible, PMA core SCKs of different sizes. In fact, SCKsac accumulated in lung, liver, and spleen significantly more than did the big SCK having the same composition. Notwithstanding the higher accumulation in RES and non-RES organs, SCKsac exhibited a slightly but significantly higher blood retention $(\mathrm{P}<0.001)$ compared to SCKbac at each considered time point (Figure 1).

Evidence of the importance of the chemical composition in providing SCKs a long-circulation in blood comes from the comparison of SCKssc and SCKsac biodistribution data. In spite of the similar size, SCKssc shows a considerably higher accumulation and longer retention in blood compared to SCKsac out to $24 \mathrm{~h}$ p.i. Furthermore, SCKssc burden in liver, lung, and spleen is lower than SCKsac at early time points (10 min and $1 \mathrm{~h}$ p.i.).

These findings suggest that the chemical composition of the core domain and nanoparticle size have synergistic roles in influencing the biological behavior of SCKs. This is reasonable since particles escape the blood circulation through sinusoidal capillaries (such as in the endothelium of liver, bone marrow, lymph nodes, and spleen), due to paracellular gaps, or in tissues where the integrity of endothelial barrier is compromised (such as in inflamed tissues and tumors) if their size and rigidity/flexibility allow them to adapt to the size and shape of the substrate. Therefore, since the SCK surface contact area changes with size and shape adaptability, SCK size and composition are both critical factors in determining the effective, biologically-active particle size and are both important when interfacial interactions are present, that is, in biological systems.

\section{Conclusions}

We have synthesized and characterized a series of four SCK nanoparticles, each with and without surface PEG derivatization, utilizing two different core compositions and two distinct size distributions. A method was developed to conjugate a TETA derivative within the shells of the nanoparticles, and each of the nanoconjugates was radiolabeled with ${ }^{64} \mathrm{Cu}$ in good radiochemical yields and high radiochemical purity. We then evaluated their in vivo behaviors in normal rodents by using biodistribution and small animal PET imaging approaches. In vivo, surface derivatization with PEG was determined to improve the blood circulation time of the SCK populations containing fluid-like poly(methyl acrylate) cores, but had no significant effects on accumulation in other organs.

Among the nanoconjugates studied, the $18 \mathrm{~nm}$ core-shell nanoparticle with a rigid polystyrene core (SCKssc) showed the longest blood retention and lowest liver accumulation. These results highlight the need to scrutinize carefully the size, flexibility, and surface chemistry of a given nanoparticle during the design process, and have shown that relatively small physico-chemical differences have significant biological implications. This detailed in vivo assessment should have a significant impact on the design of future nanoconjugates for use in biological systems 
as shell crosslinked nanoparticles are rapidly evolving into a versatile polymeric nano-platform for drug delivery and therapy to cancer and other malignancies.

\section{Supplementary Material}

Refer to Web version on PubMed Central for supplementary material.

\section{Aknowledgement}

The authors would like to thank Nicole Fettig, John Engelbach, Lynne Jones, and Terry Sharp for technical assistance in the biodistribution and microPET imaging studies, Jerrel Rutlin for quantitative analysis of the microPET images, and M. Cecilia Giron for data analysis. This research was supported by an NCI/NASA contract under the Fundamental Technologies for Biomolecular Sensors program (N01-CO-27103), and CBI Program Training Fellowships (J.L.T, M.L.B., and M.J.J.) at Washington University funded by the NIH-NRSA (5-T32-GM08785-02). The copper-64 was provided by Washington University School of Medicine and partially funded through an NCI grant R24 CA86307 (M.J.W.).

\section{References}

1. Gao Z, Fain HD, Rapoport N. Mol. Pharm 2004;1:317-330. [PubMed: 15981591]

2. Torchilin VP. J. Control. Release 2001;73:137-172. [PubMed: 11516494]

3. Geyer RP. Fette Med 1967;6:59-61.

4. Rolland, A., editor. Pharmaceutical Particulate Carriers: Therapeutic Applications. New York: Marcel Dekker; 1993.

5. Torchilin, VP., editor. Immobilized Enzymes in Medicine (Progress in Clinical Biochemistry), Vol 11. Berlin, Germany: Springer-Verlag; 1991.

6. Gregoriadis, G., editor. Liposomes as Drug Carriers: Recent Trends and Progress. Chichester, UK: John Wiley and Sons; 1988.

7. Dong Y, Feng SS. Biomaterials 2004;25:2843-2849. [PubMed: 14962562]

8. Zhang Y, Zhuo RX. Biomaterials 2004;26:2089-2094. [PubMed: 15576183]

9. Gref R, Minamitake Y, Peracchia MT, Trubetskoy V, Torchilin VP, Langer R. Science 1994;263:16001603. [PubMed: 8128245]

10. Vandorpe J, Schacht E, Dunn SE, Hawley A, Stolnick S, Davis SS, Garnett MC, Davies MC, Illum L. Biomaterials 1997;18:1147-1152. [PubMed: 9259511]

11. Lukyanov AN, Torchilin VP. Adv. Drug Deliv. Rev 2004;56:1273-1289. [PubMed: 15109769]

12. Lukyanov AN, Hartner WC, Torchilin VP. J. Control. Release 2004;94:187-193. [PubMed: 14684282]

13. Gao Z, Lukyanov AN, Chakilam AR, Torchilin VP. J. Drug Target 2003;11:87-92. [PubMed: 12881194]

14. Lizano C, Weissig V, Torchilin VP, Sancho P, Garcia-Perez AI, Pinilla M. Eur. J. Pharm. Biopharm 2003;56:153-157. [PubMed: 12957627]

15. Lukyanov AN, Gao Z, Torchilin VP. J. Control. Release 2003;91:97-102. [PubMed: 12932641]

16. Moghimi SM, Hunter AC, Murray JC. Pharm. Rev 2001;53:283-318. [PubMed: 11356986]

17. Jones M, Leroux J. Eur. J. Pharm. Biopharm 1999;48:101-111. [PubMed: 10469928]

18. Torchilin VP. J. Microencapsul 1998;15:1-19. [PubMed: 9463803]

19. Hagan SA, Coombes AGA, Garnett MC, Dunn SE, Davis MC, Illum L, Davis SS, Harding SE, Purkiss S, Gellert PR. Langmuir 1996;12:2153-2161.

20. Trubetskoy VS, Torchilin VP. Adv. Drug Deliv. Rev 1995;16:311-320.

21. Torchilin VP, Trubetskoy VS, Whiteman KR, Caliceti P, Ferruti P, Veronese FM. J. Pharm. Sci 1995;84:1049-1053. [PubMed: 8537880]

22. Allen TM, Hansen C. Biochim. Biophys. Acta 1991;1068:133-141. [PubMed: 1911826]

23. Lee J, Martic PA, Tan JS. J. Colloid Interface Sci 1989;131:252-266. 
24. Lasic DD, Martin FJ, Gabizon A, Huang SK, Papahadjopoulos D. Biochim. Biophys. Acta 1991;1070:187-192. [PubMed: 1751525]

25. Donbrow M. Microcapsules Nanopart. Med. Pharm. 1992:219-237.

26. Bazile D, Verrecchia T, Bassoulet MT, Marlard M, Spenlehauer G, Veillard M. Yakuzaigaku 1993;53:10-13.

27. Verrecchia T, Huve P, Bazile D, Veillard M, Spenlehauer G, Couvreur P. J. Biomed. Mater. Res 1993;27:1019-1028. [PubMed: 8408114]

28. Mueller RH, Wallis KH, Troester SD, Kreuter J. J. Control. Release 1992;20:237-246.

29. Neradovic D, Soga O, Van Nostrum CF, Hennink WE. Biomaterials 2004;25:2409-2418. [PubMed: 14741606]

30. Chaw CS, Chooi KW, Liu XM, Tan CW, Wang L, Yang YY. Biomaterials 2004;25:4297-4308. [PubMed: 15046920]

31. Yokoyama M, Miyauchi M, Yamada N, Okano T, Sakurai Y, Kataoka K, Inoue S. Cancer Res 1990;50:1700-1703.

32. Yokoyama M, Okano T, Sakurai Y, Ekimoto H, Shibazaki C, Kataoka K. Cancer Res 1991;51:3229_ 3236. [PubMed: 2039998]

33. Yokoyama M. Crit. Rev. Ther. Drug Carrier Syst 1992;9:213-248. [PubMed: 1458544]

34. Zhang X, Burt HM, Mangold G, Dexter D, Von Hoff D, Mayer L, Hunter WL. Anti-Cancer Drugs 1997;8:686-701. [PubMed: 9311445]

35. Zhang X, Burt HM, Von Hoff D, Dexter D, Mangold G, Degen D, Okataba AM, Hunter WL. Cancer Chemother. Pharmacol 1997;40:81-86. [PubMed: 9137535]

36. Kwon G, Suwa S, Yokoyama M, Okano T, Sakurai Y, Kataoka K. Pharm. Rev. (NY) 1993;10:970974.

37. Kwon G, Suwa S, Yokoyama M, Okano T, Sakurai Y, Kataoka K. J. Control. Release 1993;29:1723.

38. Allen C, Maysinger D, Eisenberg A. Colloids and Surfaces B: Biointerfaces 1999;16:3-27.

39. Wooley KL. J. Polym. Sci. Part A Polym. Chem 2000;38:1397-1407.

40. Thurmond KBI, Kowalewski T, Wooley KL. J. Am. Chem. Soc 1996;118:7239-7240.

41. Thurmond KBI, Kowalewski T, Wooley KL. J. Am. Chem. Soc 1997;119:6656-6665.

42. Remsen EE, Thurmond KB II, Wooley KL. Macromolecules 1999;32:3685-3689.

43. Kao HM, O'Connor RD, Mehta AK, H H, Poliks B, Wooley KL, Schaefer J. Macromolecules 2001;34:544-546.

44. Thurmond KB II, Remsen EE, Kowalewski T, Wooley KL. Nucleic Acids. Res 1999;27:2966-2971. [PubMed: 10390540]

45. Becker ML, Bailey LO, Wooley KL. Bioconjug. Chem 2004;15:710-717. [PubMed: 15264857]

46. Liu J, Zhang Q, Remsen EE, Wooley KL. Biomacromolecules 2001;2:362-368. [PubMed: 11749193]

47. Pan D, Turner JL, Wooley KL. Chem. Commun. (Camb.) 2003:2400-2401. [PubMed: 14587701]

48. Joralemon MJ, Murthy KS, Remsen EE, Becker ML, Wooley KL. Biomacromolecules 2004;5:903913. [PubMed: 15132680]

49. Buetuen V, Billingham NC, Armes SP. J. Am. Chem. Soc 1998;120:12135-12136.

50. Becker ML, Liu J, Wooley KL. Chem. Commun. (Camb.) 2003:180-181. [PubMed: 12585380]

51. Anderson CJ, Connett JM, Schwarz SW, Rocque PA, Guo LW, Philpott GW, Zinn KR, Meares CF, Welch MJ. J. Nucl. Med 1992;33:1685-1691. [PubMed: 1517844]

52. Anderson CJ, Rocque PA, Weinheimer CJ, Welch MJ. Nucl. Med. Biol 1993;20:461-467. [PubMed: 8504288]

53. Anderson CJ, Welch MJ. Chem. Rev 1999;99:2219-2234. [PubMed: 11749480]

54. Anderson CJ, Dehdashti F, Cutler PD, Schwarz SW, Laforest R, Bass LA, Lewis JS, McCarthy DW. J. Nucl. Med 2001;42:213-221. [PubMed: 11216519]

55. Rogers BE, Bigott HM, McCarthy DW, Della Manna D, Kim J, Sharp TL, Welch MJ. Bioconjug. Chem 2003;14:756-763. [PubMed: 12862428]

56. Philpott GW, Schwarz SW, Anderson CJ, Dehdashti F, Connett JM, Zinn KR, Meares CF, Cutler PD, Welch MJ, Siegel BA. J. Nucl. Med 1995;36:1818-1824. [PubMed: 7562049] 
57. Li WP, Lewis JS, Kim J, Bugaj JE, Johnson MA, Erion JL, Anderson CJ. Bioconjug. Chem 2002;13:721-728. [PubMed: 12121126]

58. Anderson CJ, Jones LA, Bass LA, Sherman ELC, McCarthy DW, Cutler PD, Lanahan MV, Cristel ME, Lewis JS, Schwarz SW. J. Nucl. Med 1998;39:1944-1951. [PubMed: 9829587]

59. Lewis JS, R LM, Cutler PD, Srinivasan A, Schmidt MA, Schwarz SW, Morris MM, Miller JP, Anderson CJ. Clin. Cancer Res 1999;5:3608-3616. [PubMed: 10589778]

60. Lewis JS, Laforest R, Lewis MR, Anderson CJ. Cancer Biother. Radiopharm 2000;15:593-604. [PubMed: 11190491]

61. Connett JM, Anderson CJ, Guo LW, Schwarz SW, Zinn KR, Rogers BE, Siegel BA, Philpott GW, Welch MJ. Proc. Natl. Acad. Sci. U. S. A 1996;93:6814-6818. [PubMed: 8692901]

62. Zimmermann K, Grunberg J, Honer M, Ametamey S, Schubiger PA, Novak-Hofer I. Nucl. Med. Biol 2003;30:417-427. [PubMed: 12767399]

63. McCarthy DW, Bass LA, Cutler PD, Shefer RE, Klinkowstein RE, Herrero P, Lewis JS, Cutler CS, Anderson CJ, Welch MJ. Nucl. Med. Biol 1999;26:351-358. [PubMed: 10382836]

64. McCarthy DW, Shefer RE, Klinkowstein RE, Bass LA, Margeneau WH, Cutler CS, Anderson CJ, Welch MJ. Nucl. Med. Biol 1997;24:35-43. [PubMed: 9080473]

65. Zuckerman RN, Martin EJ, Spellmeyer DC, Stauber GB, Showemaker KR, Kerr JM, Figliozzi GM, Goff DA, Siani MA, Simon RJ, Banville SC, Brown EG, Wang L, Richter LS, Moos WH. J. Med. Chem 1994;37:2678-2685. [PubMed: 8064796]

66. Lewis MR, Boswell CA, Laforest R, Buettner TL, Ye D, Connett JM, Anderson CJ. Cancer Biother. Radiopharm 2001;16:483-494. [PubMed: 11789025]

67. Lewis MR, Kao JY, Anderson AL, Shively JE, Raubitschek A. Bioconjug. Chem 2001;12:320-324. [PubMed: 11312695]

68. Knoess C, Siegel S, Smith A, Newport D, Richerzhagen N, Winkeler A, Jacobs A, Goble RN, Graf R, Wienhard K, Heiss WD. Eur. J. Nucl. Med. Mol. Imaging 2003;30:737-747. [PubMed: 12536244]

69. Patlack CS, Blasberg RG, Fenstermacher JD. J. Cereb. Blood Flow Metab 1983;3:1-7. [PubMed: 6822610]

70. Becker ML, Liu J, Wooley KL. Biomacromolecules 2005;6:220-228. [PubMed: 15638524]

71. Sun X, Anderson CJ. Methods Enzymol 2004;386:237-261. [PubMed: 15120255]

72. Murthy KS, Ma Q, Remsen EE, Kowalewski T, Wooley KL. J. Mater. Chem 2003;13:2785-2795.

73. Takeoka S, Teramura Y, Okamura Y, Tsuchida E, Handa M, Ikeda Y. Bioch. Biophys. Res. Comm 2002;191:765-770.

74. Klibanov AL, Maruyama K, Torchilin VP, Huang L. FEBS Lett 1990;268:235-237. [PubMed: 2384160]

75. Torchilin VP, Trubetskoy VS. Adv. Drug Deliv. Rev 1995;16:141-155. 

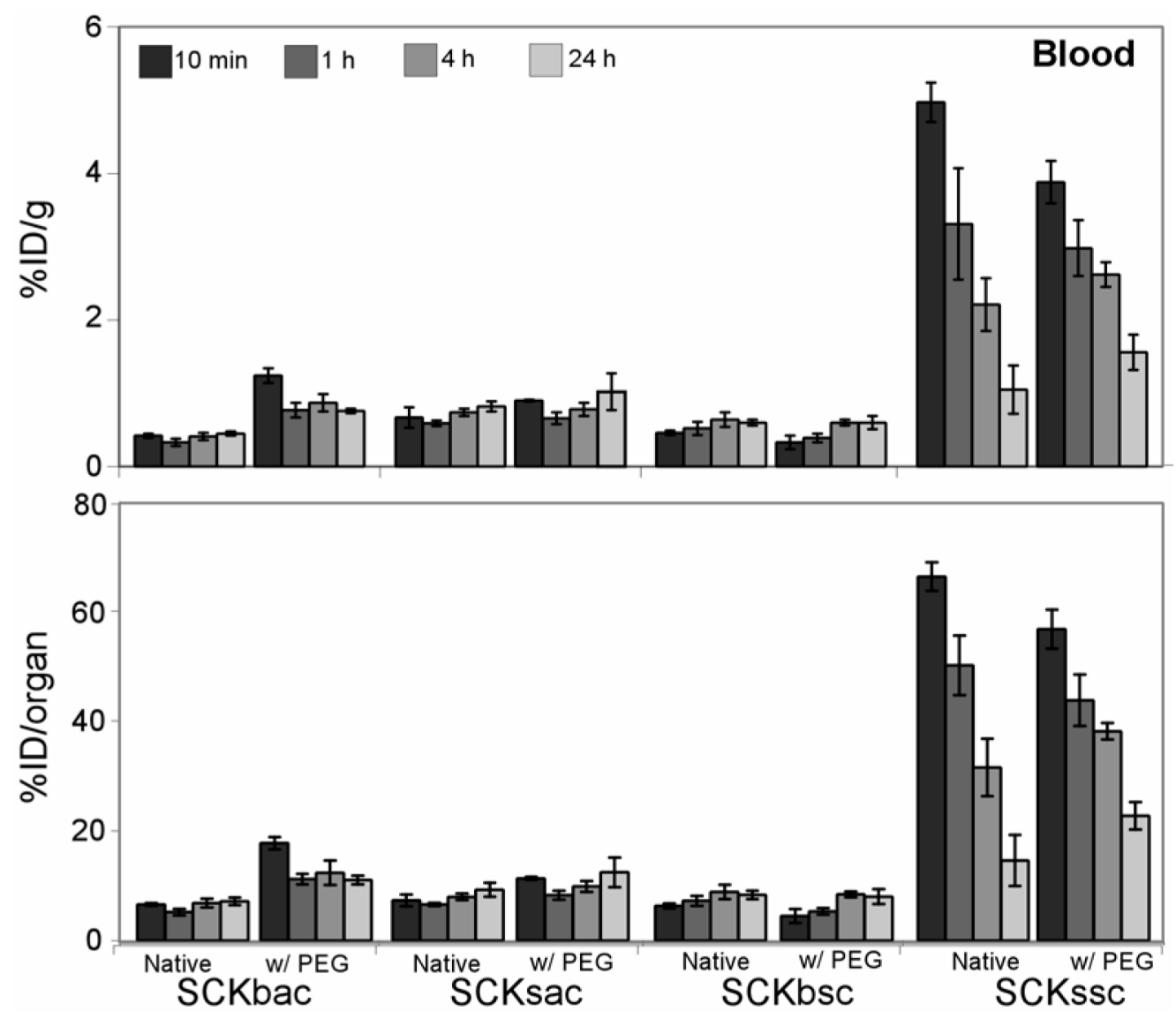

Figure 1.

Blood biodistribution data of ${ }^{64} \mathrm{Cu}$-radiolabeled SCK before and after PEGylation in normal Sprague-Dawley rats $(\mathrm{n}=4$; ANOVA, $\mathrm{P}<0.0001)$. Data are present as percent injected dose per gram tissue (\%ID/g, top) and percent injected dose per organ (\%ID/organ, bottom) \pm standard deviation. The numerical data and standard deviations for these graphs are listed in supporting information. 

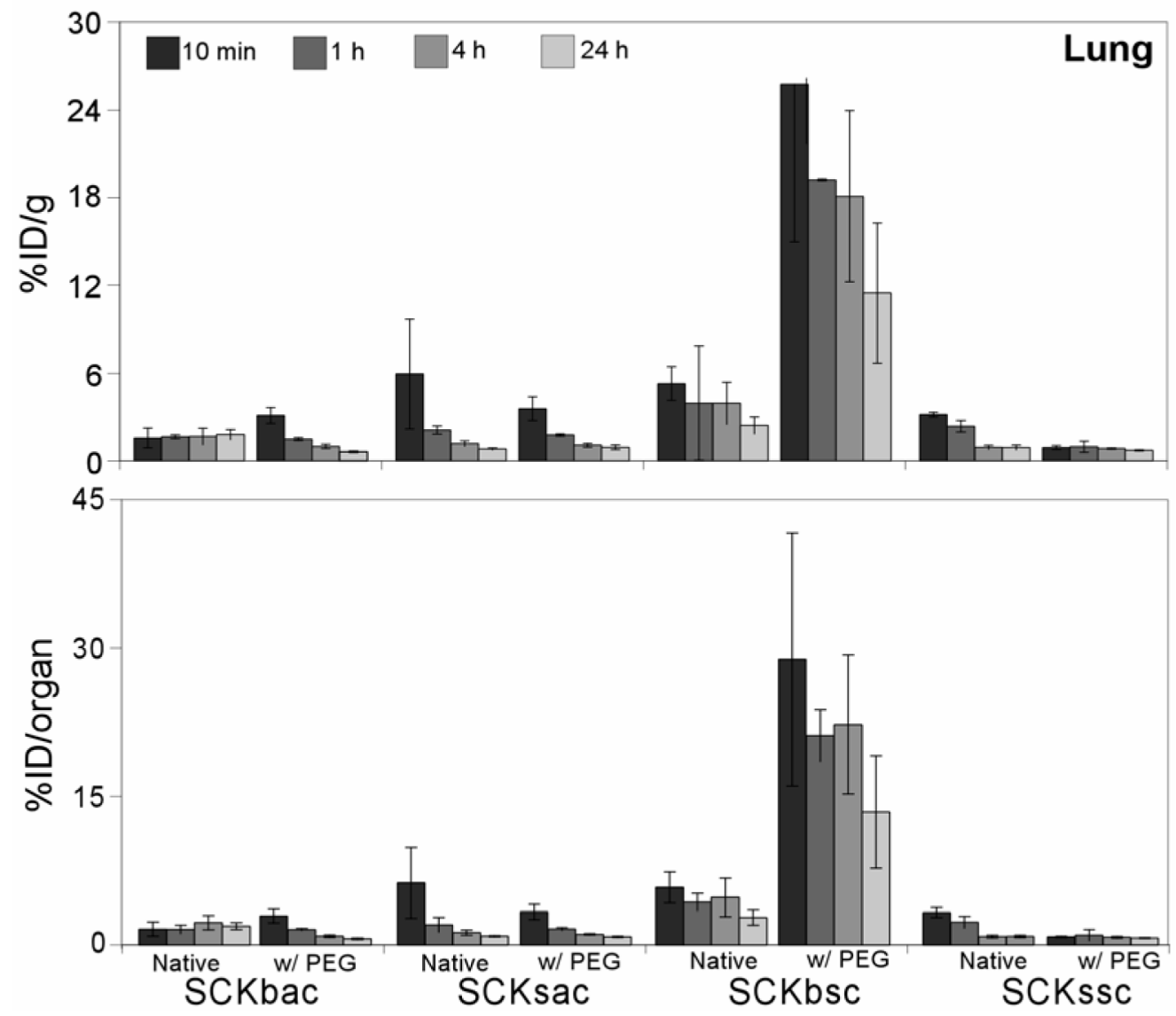

Figure 2.

Biodistribution data of ${ }^{64} \mathrm{Cu}$-radiolabeled SCKs before and after PEGylation in the lung of normal Sprague-Dawley rats $(\mathrm{n}=4$; ANOVA, $\mathrm{P}<0.0001)$. Data are present as percent injected dose per gram tissue (\%ID/g, top) and percent injected dose per organ (\%ID/organ, bottom) \pm standard deviation. The numerical data and standard deviations for these graphs are listed in supporting information. 

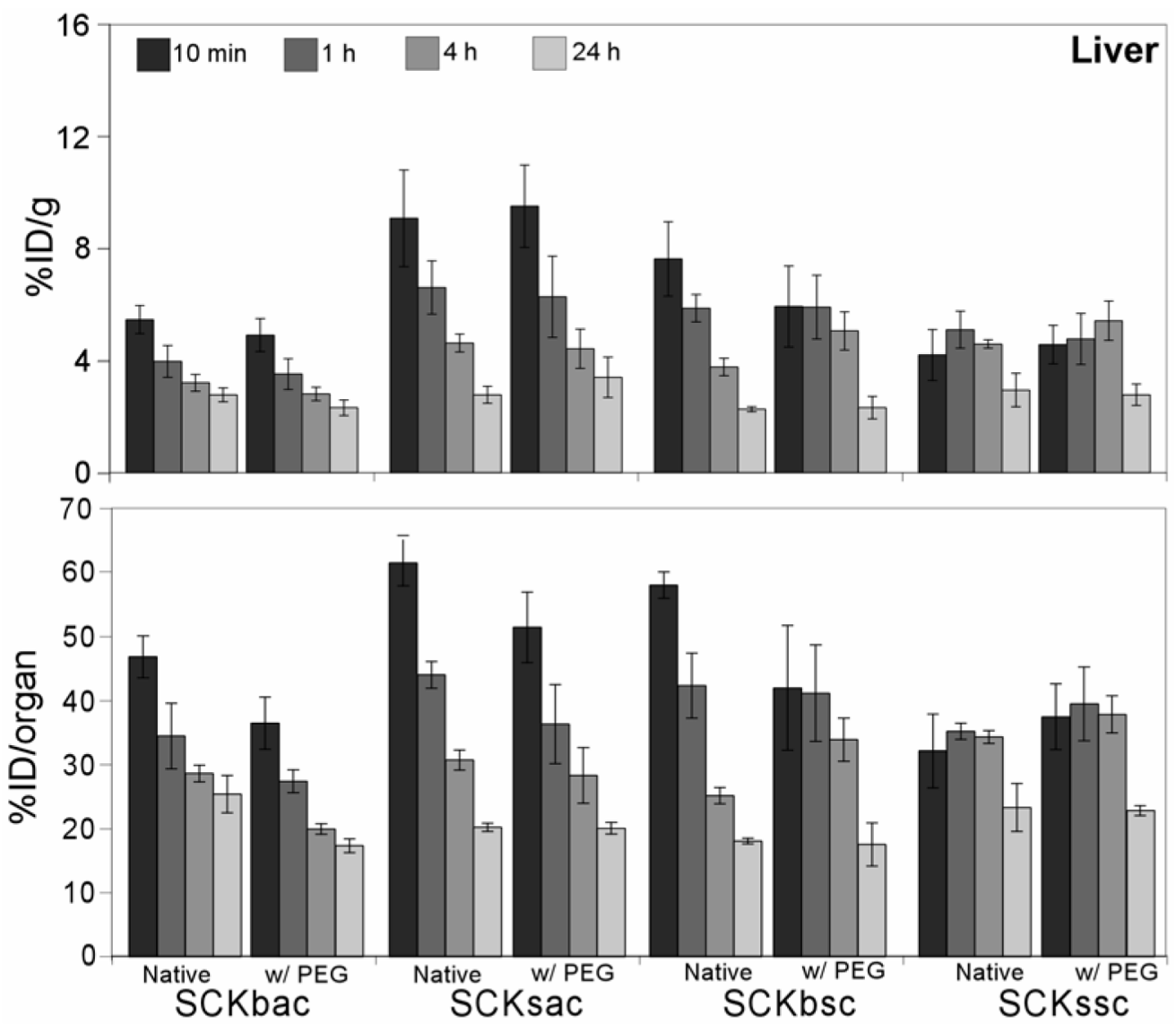

Figure 3.

Biodistribution data of ${ }^{64} \mathrm{Cu}$-radiolabeled SCKs before and after PEGylation in the liver of normal Sprague-Dawley rats $(\mathrm{n}=4$; ANOVA, $\mathrm{P}<0.0001)$. Data are present as percent injected dose per gram tissue (\%ID/g, top) and percent injected dose per organ (\%ID/organ, bottom) \pm standard deviation. The numerical data and standard deviations for these graphs are listed in supporting information. 

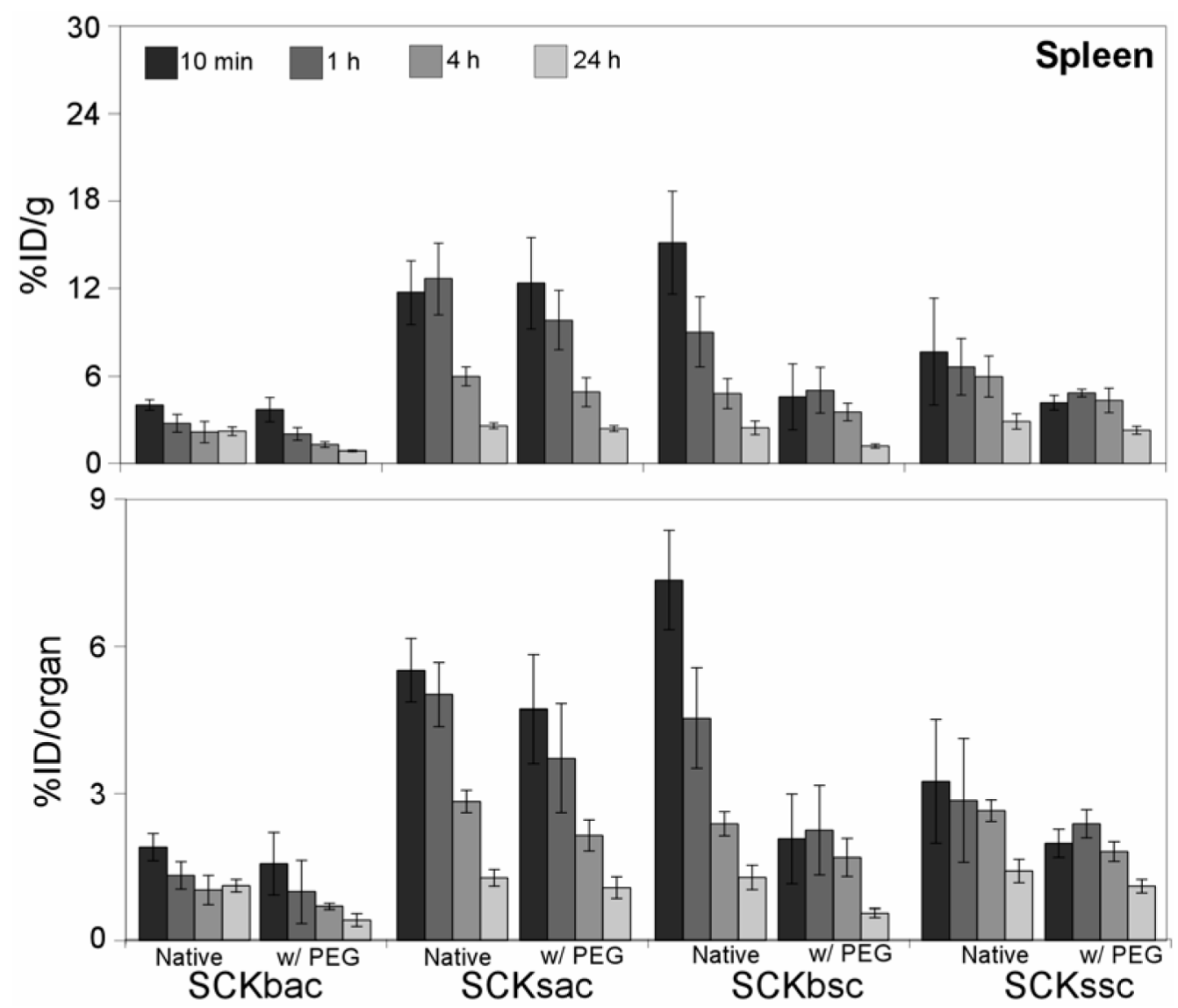

Figure 4.

Biodistribution data of ${ }^{64} \mathrm{Cu}$-radiolabeled SCKs before and after PEGylation in the spleen of normal Sprague-Dawley rats $(\mathrm{n}=4$; ANOVA, $\mathrm{P}<0.0001)$. Data are present as percent injected dose per gram tissue (\%ID/g, top) and percent injected dose per organ (\%ID/organ, bottom) \pm standard deviation. The numerical data and standard deviations for these graphs are listed in supporting information. 

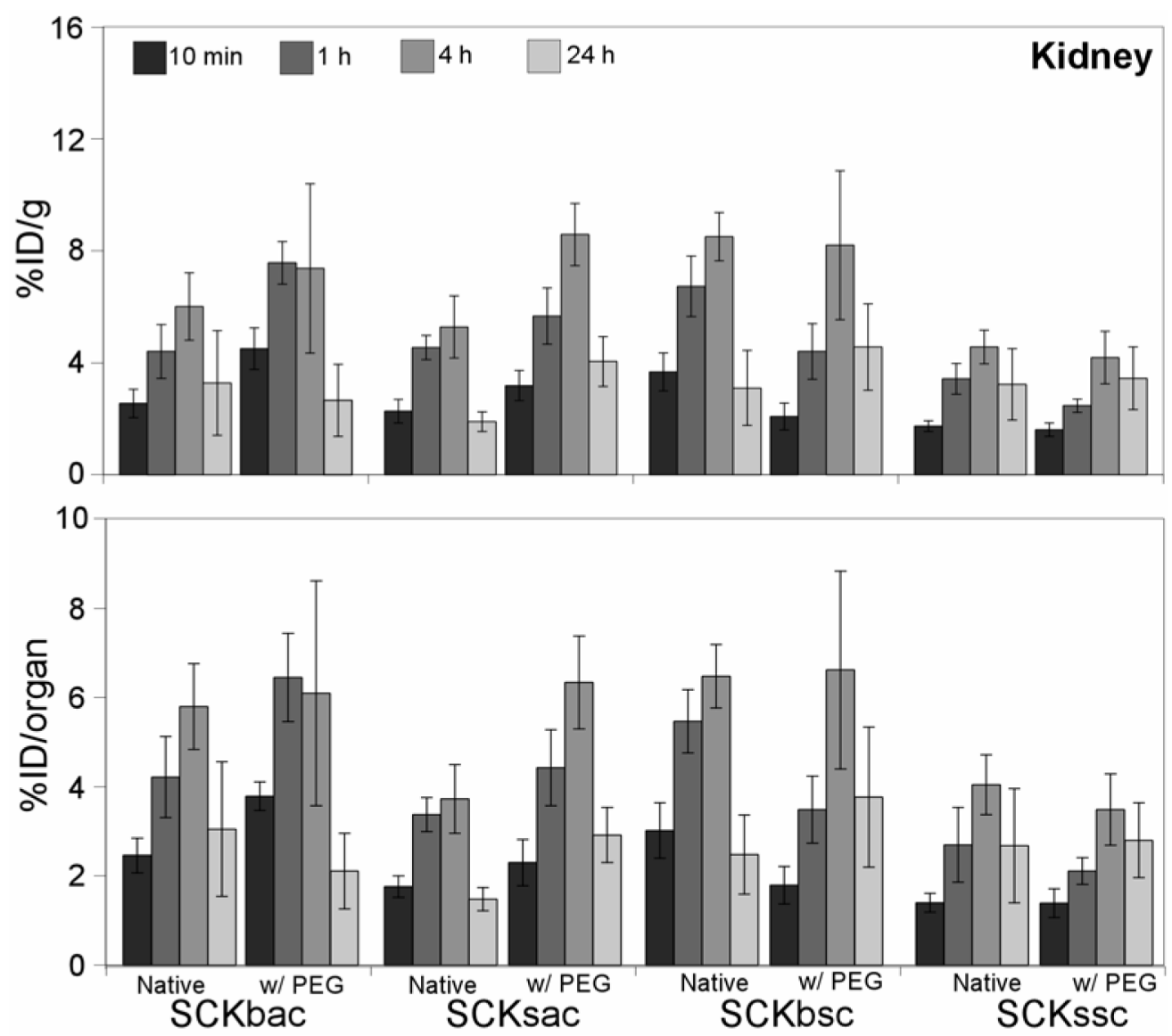

Figure 5.

Biodistribution data of ${ }^{64} \mathrm{Cu}$-radiolabeled SCKs before and after PEGylation in the kidney of normal Sprague-Dawley rats $(\mathrm{n}=4$; ANOVA, $\mathrm{P}<0.0001)$. Data are present as percent injected dose per gram tissue (\%ID/g, top) and percent injected dose per organ (\%ID/organ, bottom) \pm standard deviation. The numerical data and standard deviations for these graphs are listed in supporting information. 

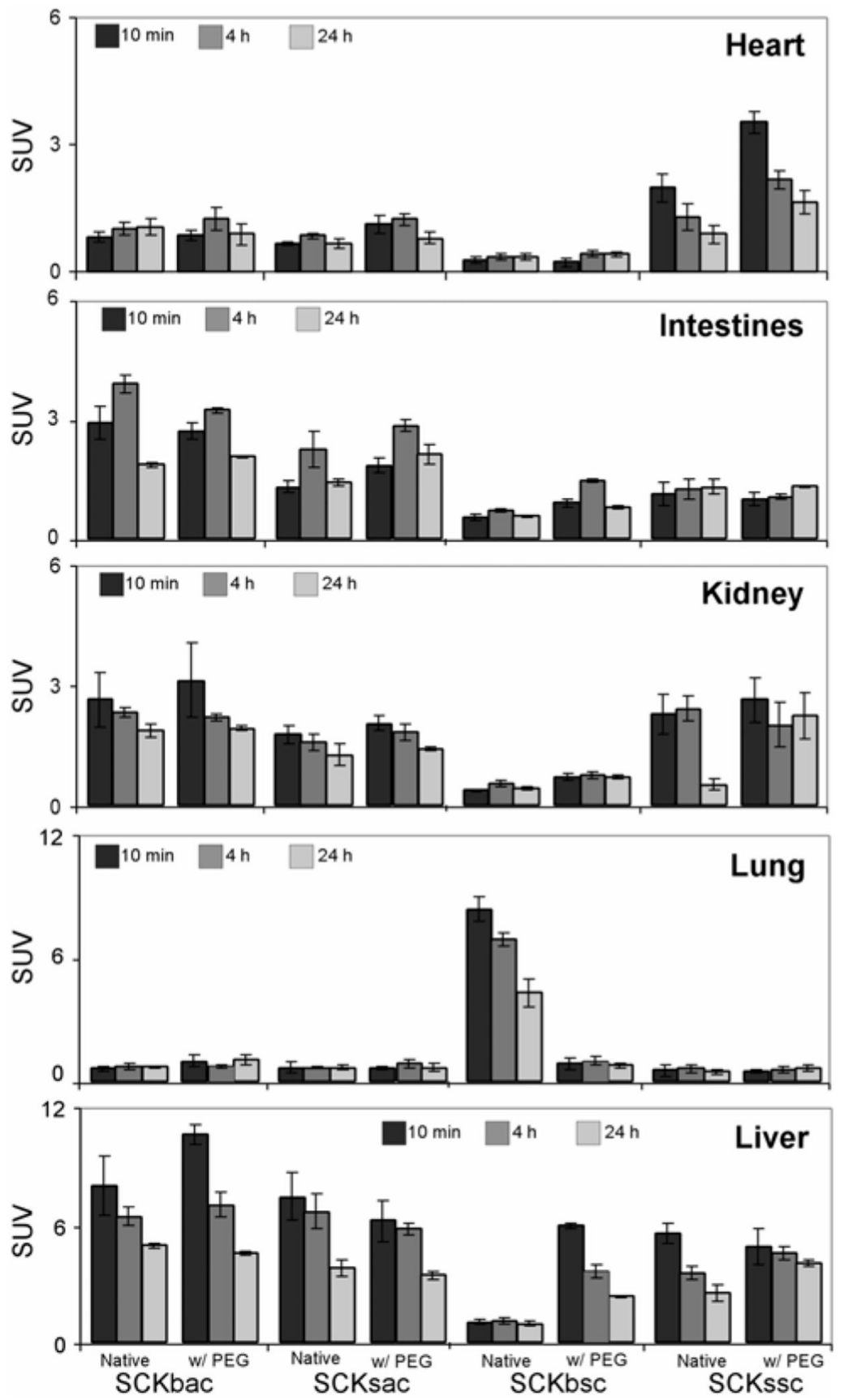

Figure 6.

Comparative organ by organ standard uptake values (SUVs) for the ${ }^{64} \mathrm{Cu}$-radiolabeled SCKs before and after PEGylation from the quantitation of MicroPET Images in normal Balb/c mice. Data are obtained from averaging multiple image slices in the selected organs, and presented as mean SUV \pm standard deviation. 

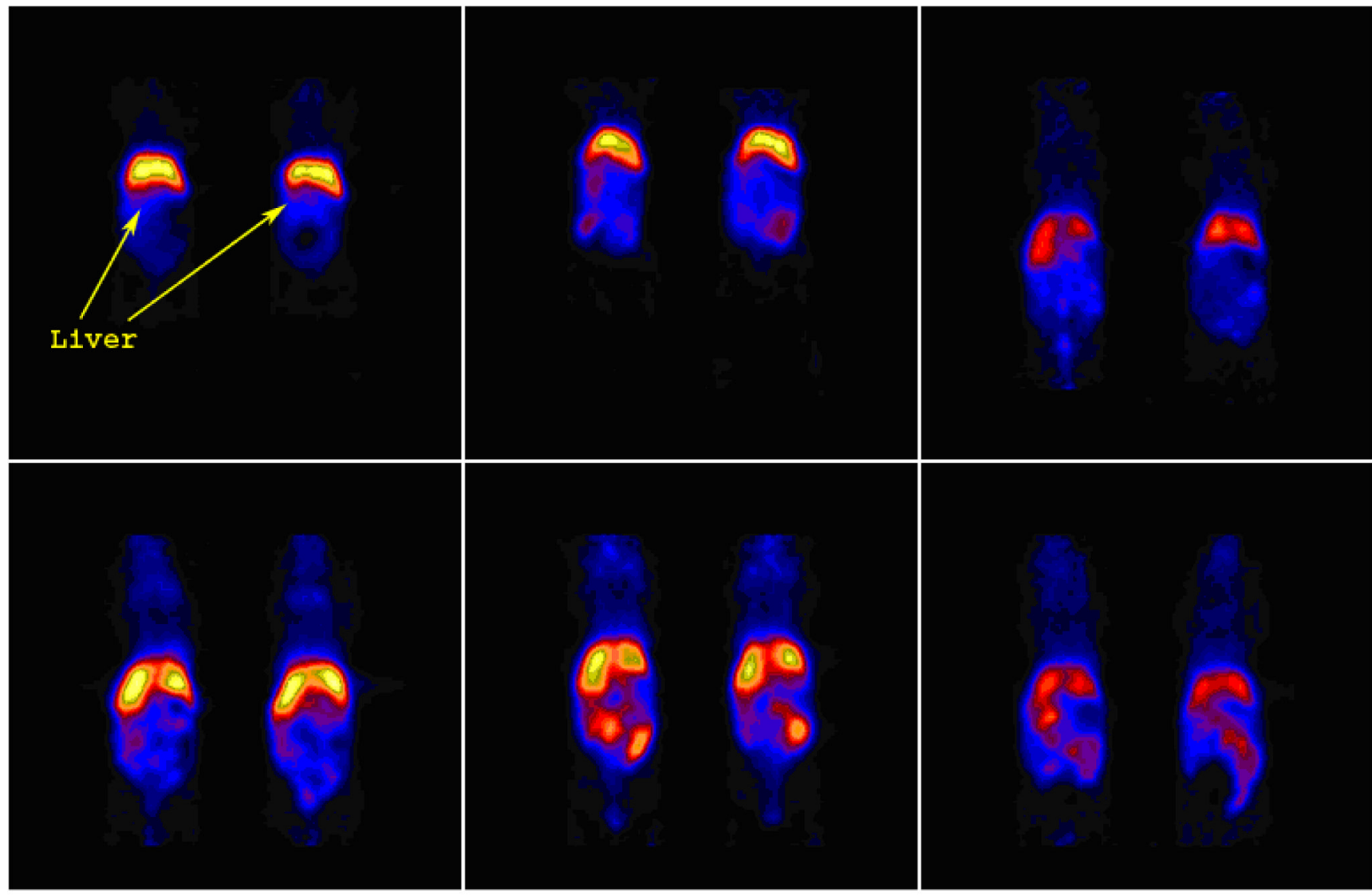

Figure 7.

The coronal microPET images of ${ }^{64} \mathrm{Cu}$-labeled SCKbac (upper panel) and PEG-SCKbac (lower panel) in normal Balb/c mice $(\mathrm{n}=2)$ at $1 \mathrm{~h}, 4 \mathrm{~h}$, and $24 \mathrm{~h}$ p.i. The imaging intensity was decay-corrected and scaled by $\max / \mathrm{min}$ frame. 
1h

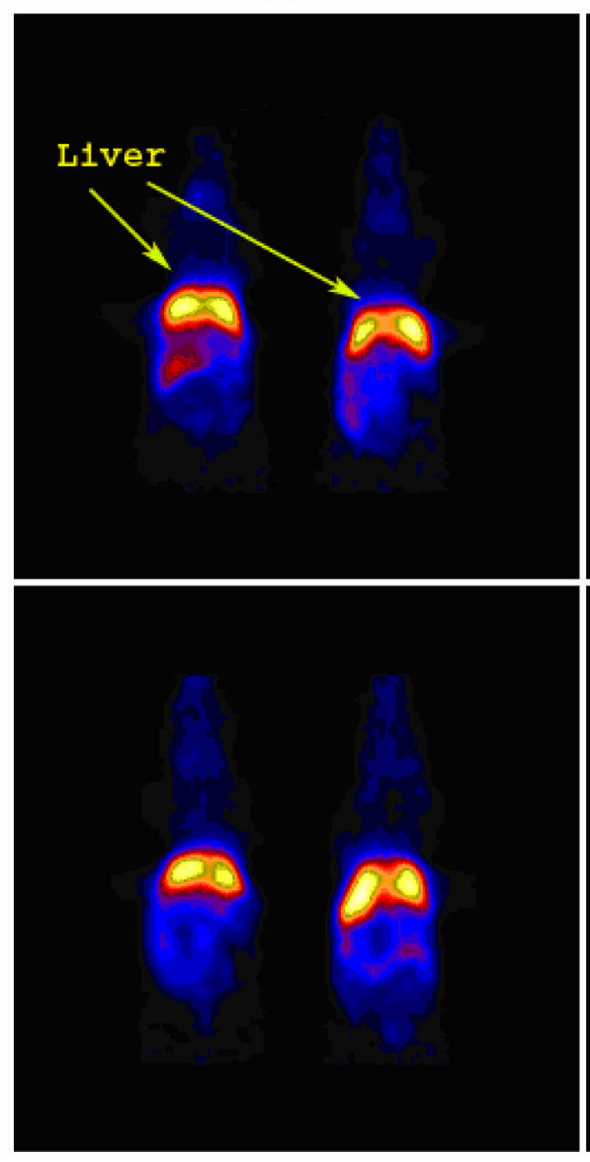

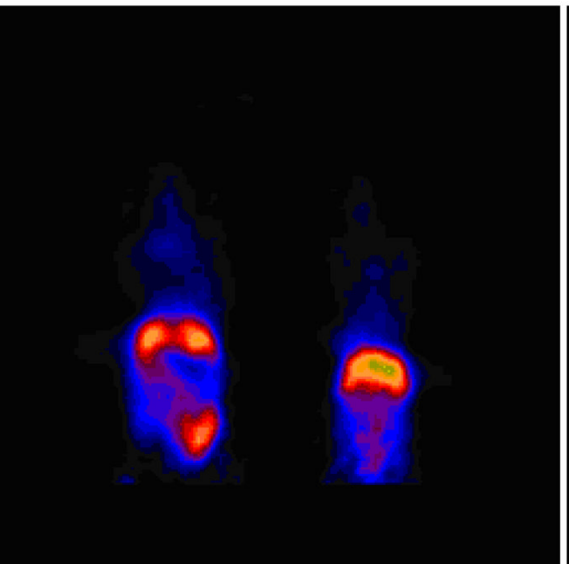

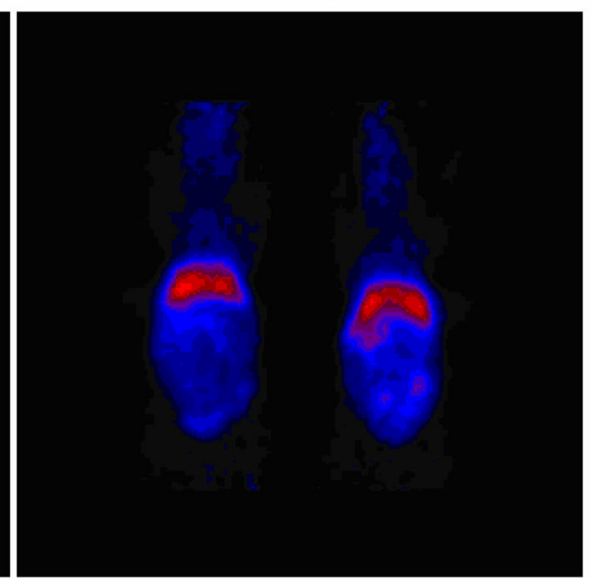

Figure 8.

The coronal microPET images of ${ }^{64} \mathrm{Cu}$-labeled SCKsac (upper panel) and PEG-SCKsac (lower panel) in normal Balb/c mice $(n=2)$ at $1 \mathrm{~h}, 4 \mathrm{~h}$, and $24 \mathrm{~h} \mathrm{p}$.i. The imaging intensity was decaycorrected and scaled by $\max / \mathrm{min}$ frame. 


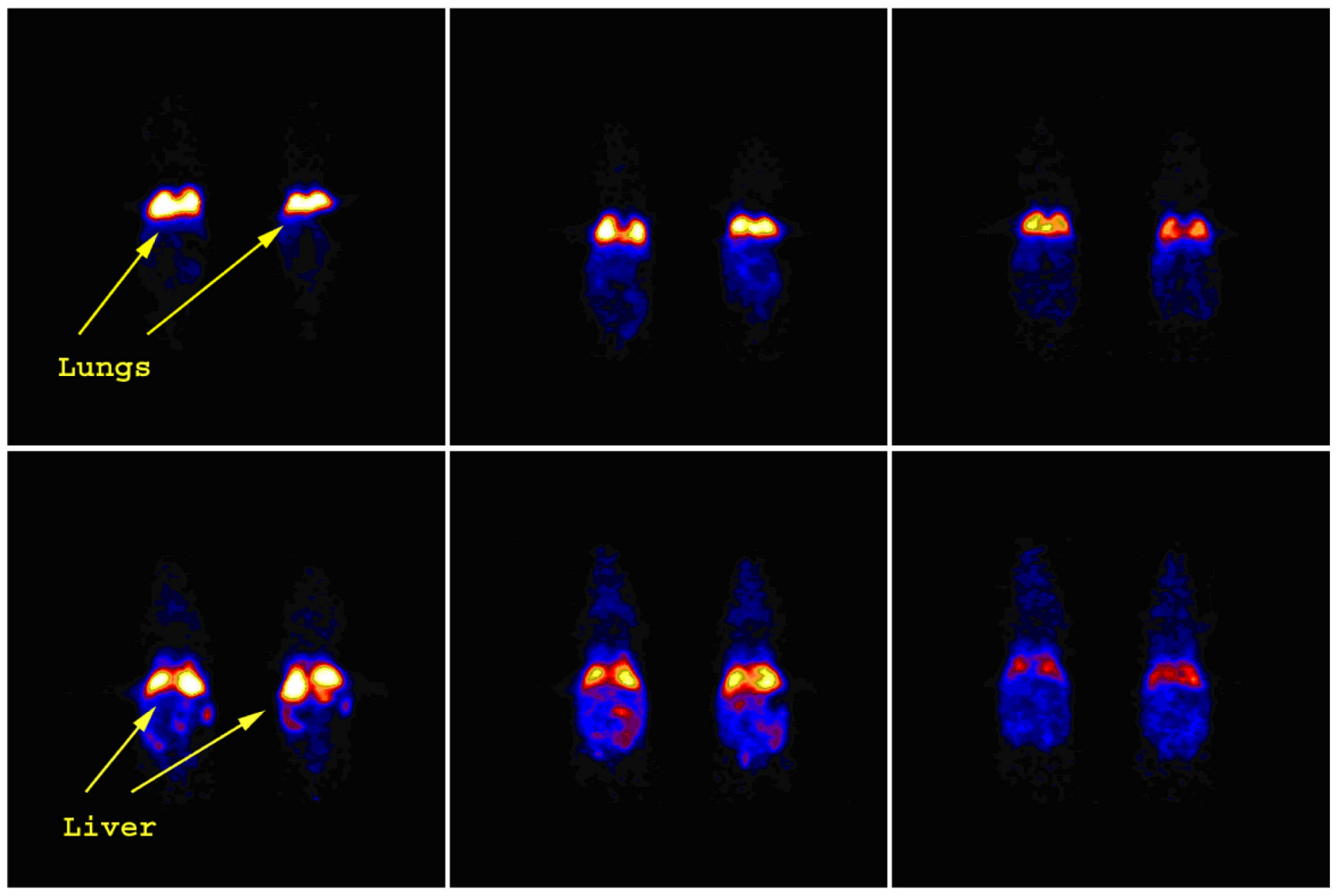

Figure 9.

The coronal microPET images of ${ }^{64} \mathrm{Cu}$-labeled SCKbsc (upper panel) and PEG-SCKbsc (lower panel) in normal Balb/c mice $(n=2)$ at $1 \mathrm{~h}, 4 \mathrm{~h}$, and $24 \mathrm{~h} \mathrm{p}$.i. The imaging intensity was decaycorrected and scaled by $\max / \mathrm{min}$ frame. 


\section{$1 \mathrm{~h}$}

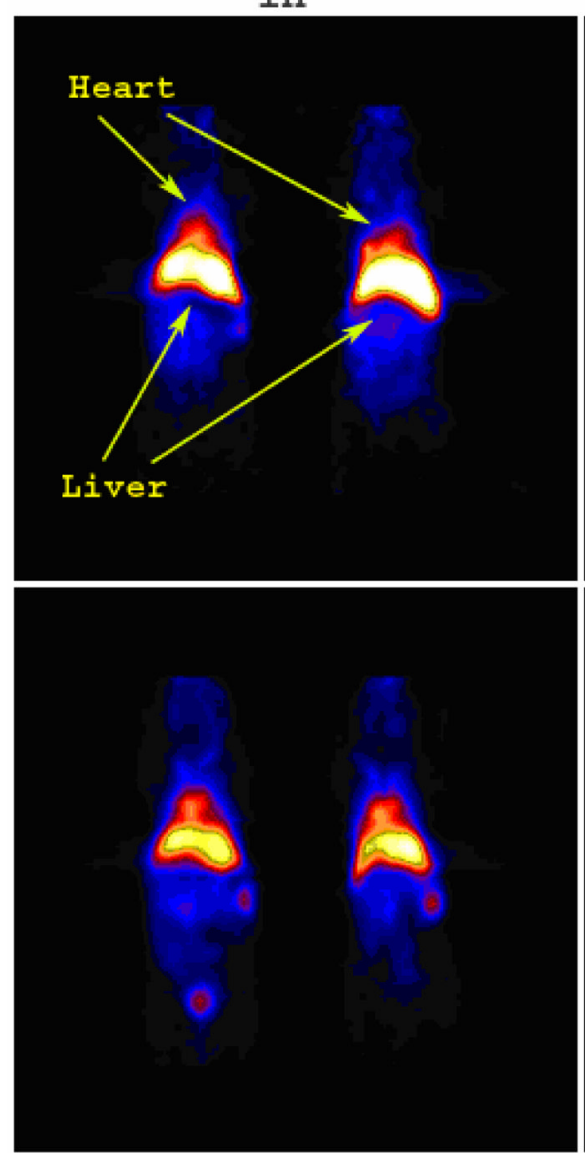

$4 \mathrm{~h}$

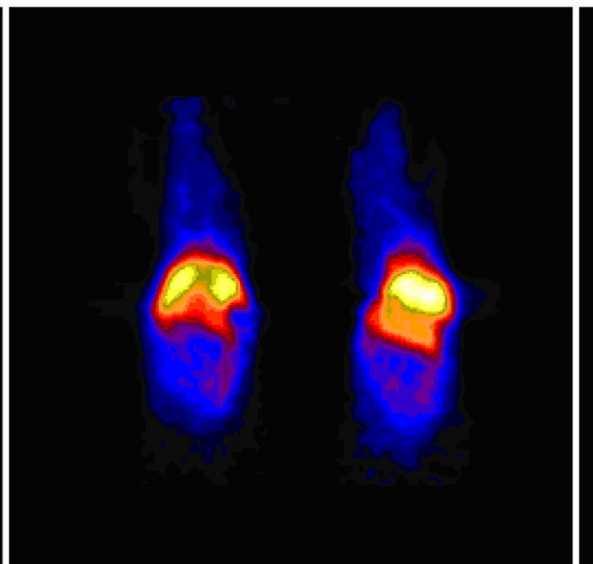

$24 \mathrm{~h}$

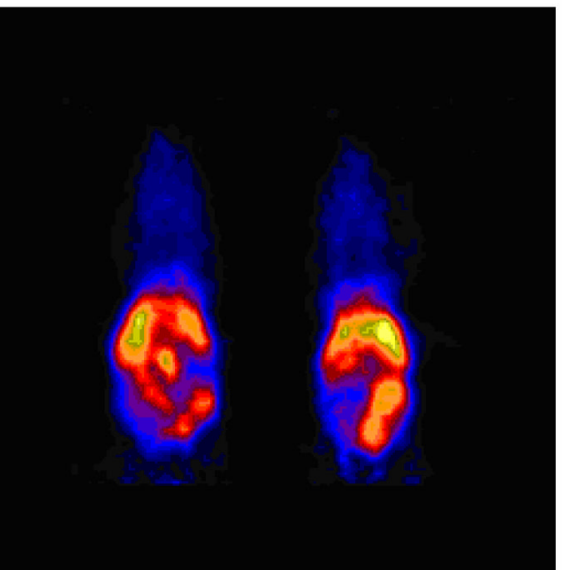

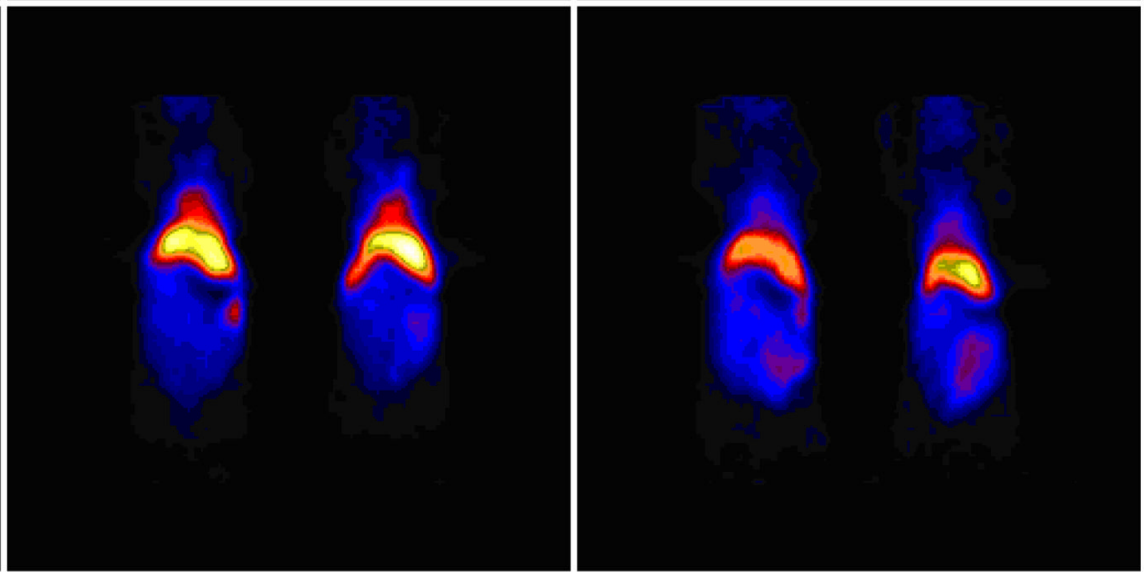

Figure 10.

The coronal microPET images of ${ }^{64} \mathrm{Cu}$-labeled SCKssc (upper panel) and PEG-SCKssc (lower panel) in normal Balb/c mice $(n=2)$ at $1 \mathrm{~h}, 4 \mathrm{~h}$, and $24 \mathrm{~h}$ p.i. The imaging intensity was decaycorrected and scaled by $\max / \mathrm{min}$ frame. 

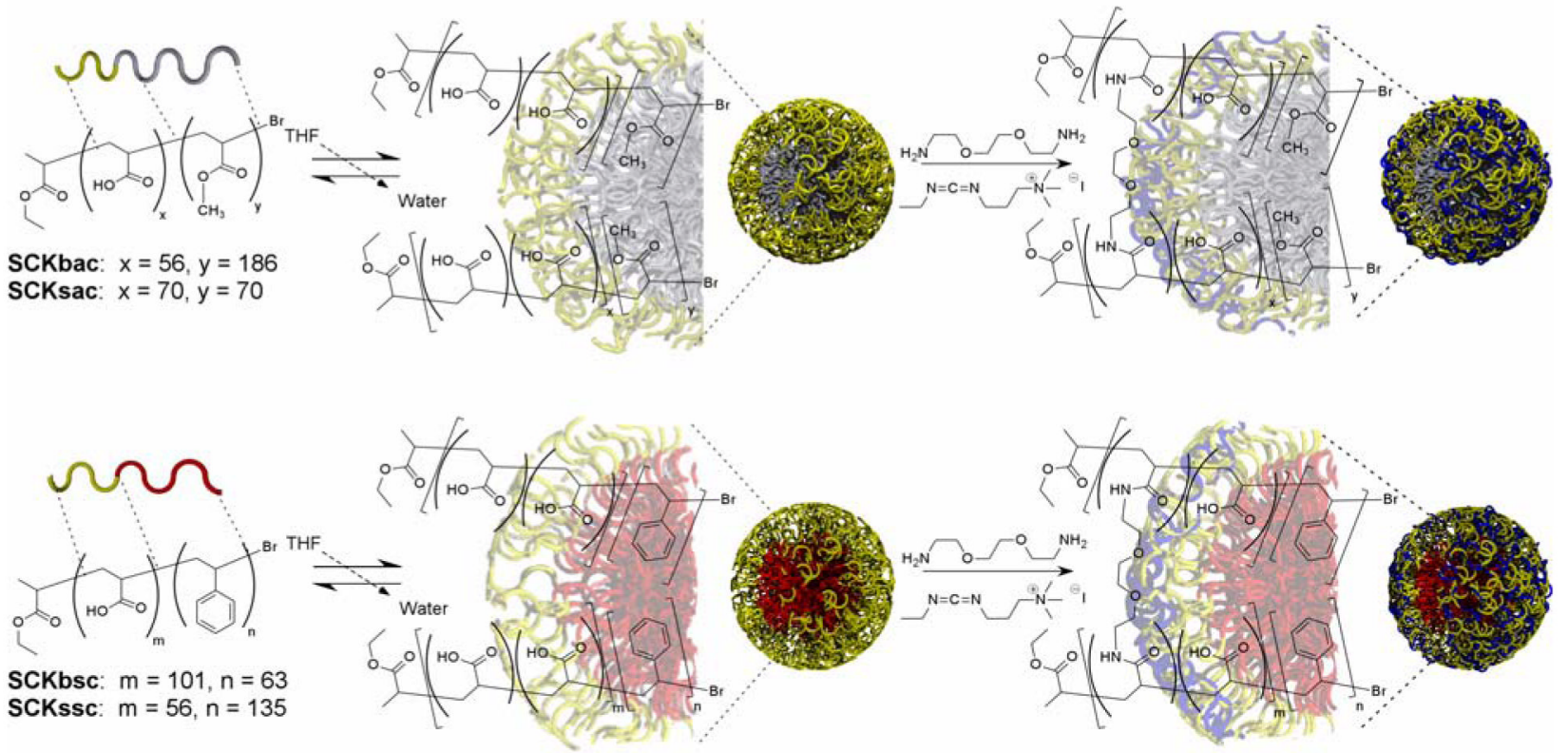

Scheme 1.

Schematic representation of SCK nanoparticle synthesis. From diblock copolymers containing either a styrene (lower panel) or methyl acrylate (upper panel) hydrophobic segment and a poly (acrylic acid) hydrophilic segment, assembly is induced through the addition of water. The resultant polymer micelle is crosslinked to nominally consume $50 \%$ of the acid residues of the block copolymer micelles upon amidation reactions with bifunctional amines. 


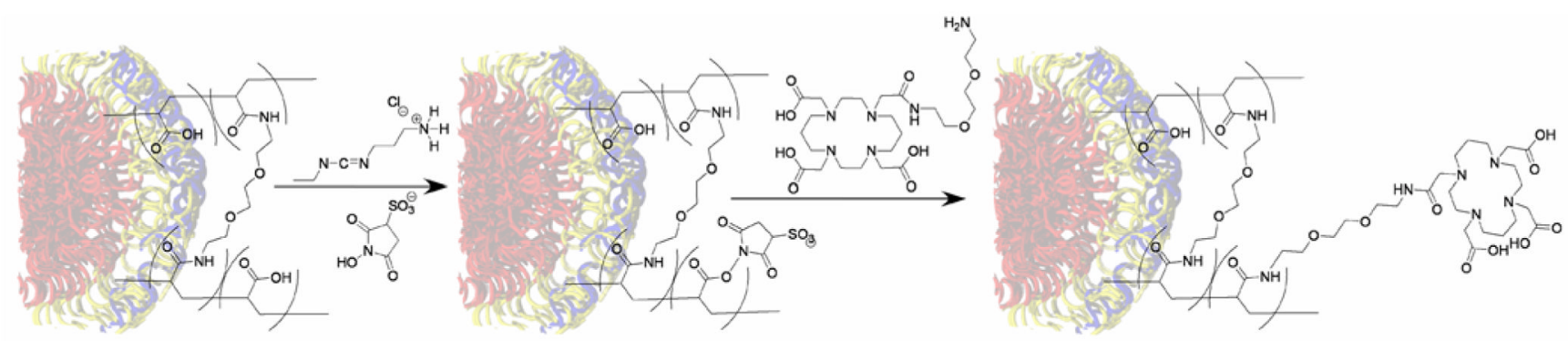

Scheme 2.

Conjugation of a macrocyclic chelator to the nanoparticles was accomplished through initial formation of activated esters within the SCK shell (carbodiimide coupling with sulfo-NHS), purification of the resultant macromolecular structure through a Centricon separation procedure, and subsequent addition of an amino derivatized TETA compound. 
Sun et al.

Page 26

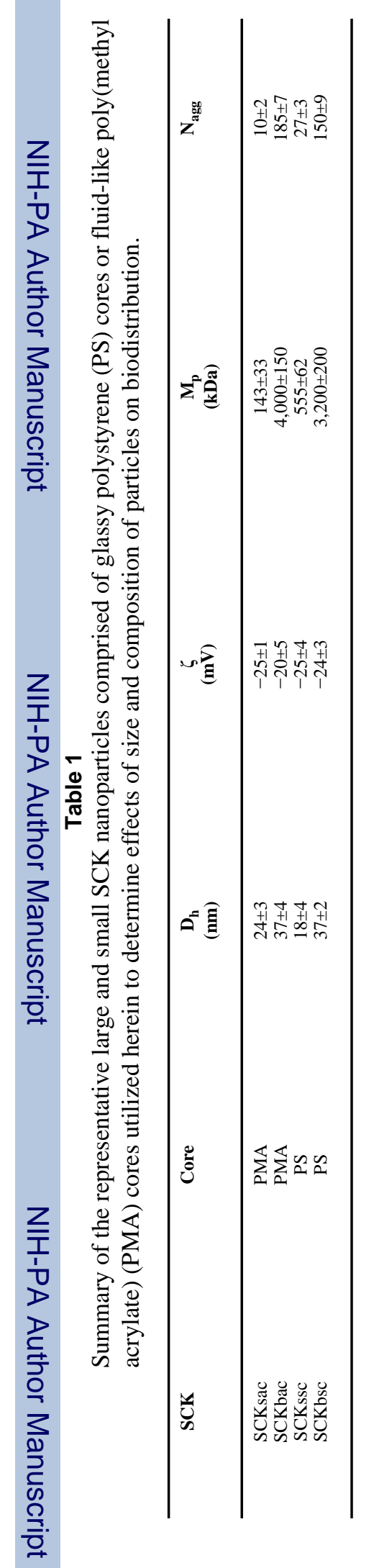

Biomacromolecules. Author manuscript; available in PMC 2008 September 11. 